\title{
Characterization of proteinase-adhesin complexes of Porphyromonas gingivalis
}

Correspondence
Eric C. Reynolds
e.reynolds@unimelb.edu.au

Received 20 December 2005

Revised 12 April 2006

Accepted 12 April 2006

\author{
Rishi D. Pathirana, Neil M. O'Brien-Simpson, Paul D. Veith, Peter F. Riley \\ and Eric C. Reynolds
}

Cooperative Research Centre for Oral Health Science, School of Dental Science, The University of Melbourne, 720 Swanston Street, Victoria, 3010, Australia

\begin{abstract}
Proteinase-adhesin complexes of Porphyromonas gingivalis wild-type and RgpA and Kgp mutants were extracted using a Triton X-114 procedure and purified using arginine-affinity chromatography. The complexes were then characterized by peptide mass fingerprinting (PMF) and their equilibrium binding constants, immunogenicity and ability to induce protection as vaccines in the murine lesion model determined. The Triton X-114 procedure resulted in consistently higher yield and specific activity of the wild-type (wt) complex compared with that produced by the previously published sonication method. PMF and N-terminal sequencing of the purified wt complex showed that it consisted of the previously identified Arg-specific proteinase $\operatorname{RgpA}_{\text {cat }}$, the Lys-specific proteinase $\mathrm{Kgp}_{\mathrm{cat}}$ and adhesin domains $\mathrm{RgpA}_{\mathrm{A} 1}, \operatorname{RgpA}_{\mathrm{A} 2}, \mathrm{RgpA}_{\mathrm{A} 3}, \mathrm{Kgp}_{\mathrm{A} 1}$ and $\mathrm{Kgp}_{\mathrm{A} 2}$. However, analysis of the $30 \mathrm{kDa}$ band in the wt complex, previously suggested to be $\operatorname{RgpA}_{\mathrm{A} 4}$, indicated that this band contained C-terminally truncated $\mathrm{Kgp}_{\mathrm{A} 1}$ (which has an identical $\mathrm{N}$-terminus to $\mathrm{RgpA}_{\mathrm{A} 4}$ ) as well as the $\mathrm{HagA}_{\mathrm{A} 1}{ }^{*}$ adhesin. Analysis of the Triton $\mathrm{X}-114$ extracted complexes from the $P$. gingivalis isogenic mutants $\mathrm{kgp}$ (RgpA complex) and $\operatorname{rgp} A$ (Kgp complex) suggested that the Kgp complex consisted of $\mathrm{Kgp}_{\mathrm{cat}}, \mathrm{Kgp}_{\mathrm{A} 1}$ and $\mathrm{Kgp}_{\mathrm{A} 2} / \mathrm{HagA} \mathrm{A}_{2}$ and that the RgpA complex consisted of $\mathrm{RgpA}_{\text {cat }}$, $\operatorname{RgpA}_{\mathrm{A} 1}, \mathrm{HagA}_{\mathrm{A} 1}{ }^{*}, \operatorname{RgpA}_{\mathrm{A} 2}$ and $\operatorname{RgpA}_{\mathrm{A} 3}$. Each of the complexes was found to have equilibrium binding constants $\left(K_{\mathrm{D}}\right)$ in the nanomolar range for fibrinogen, fibronectin, haemoglobin, collagen type $\mathrm{V}$ and laminin. However, the Triton-wt complex exhibited significantly lower $K_{\mathrm{D}}$ values for binding to each host protein compared with the sonication-wt complex, or the Triton-RgpA complex and Triton-Kgp complex. Furthermore, the Triton-wt complex induced a stronger antibody response to the $\mathrm{A} 1$ adhesins and tended to be more effective in providing protection in the mouse lesion model compared with the sonication-wt complex.
\end{abstract}

\section{INTRODUCTION}

Chronic periodontitis is a bacterial-associated inflammatory disease characterized by the destruction of the supporting tissues of the teeth. This disease is a major public health problem, with an estimated $30 \%$ of the adult dentate population affected, with severe forms affecting $5-10 \%$. The annual economic burden of the disease was estimated at US $\$ 14 \cdot 3$ billion in the USA in 1999 (Brown et al., 2000). Furthermore, chronic periodontitis may have other health implications, as several epidemiological and animal studies indicate an association between periodontitis and increased risk of cardiovascular diseases (Beck et al., 1998; Jain et al., 2003; Miyakawa et al., 2004; Wu et al., 2000), diabetes

Abbreviations: ABM, adhesin-binding motif; Bz-L-Arg-pNA, benzoyl-LArg-p-nitroanilide; CBB, Coomassie brilliant blue; IFA, incomplete Freund's adjuvant; $K_{D}$, dissociation equilibrium constant; PMF, peptide mass fingerprinting; TFA, trifluoroacetic acid; TLCK, $N \alpha$ - $p$-tosyl-lysine chloromethlyketone; wt, wild-type; z-L-Lys-pNA, benzyloxycarbonyl-LLys- $p$-nitroanilide.
(Pucher \& Stewart, 2004), rheumatoid arthritis (Mercado et al., 2001) and spontaneous preterm birth and preterm low birth weight (Lin et al., 2003; Offenbacher et al., 1998).

Colonization of the subgingival crevice by a consortium of Gram-negative bacteria with the development of a biofilm has been strongly associated with the onset and progression of chronic periodontitis (Socransky \& Haffajee, 2000). Three bacterial species within the biofilm have been strongly associated with chronic periodontitis: Porphyromonas gingivalis, Bacteroides forsythus and Treponema denticola (Socransky et al., 1998). Among these bacteria, $P$. gingivalis has received considerable attention as it has been more closely associated with disease severity (Socransky et al., 1998). Furthermore, P. gingivalis has been shown to represent up to $50 \%$ of the anaerobically cultivatable subgingival bacteria from active disease sites (Slots, 1982) and is rarely cultured from subjects without periodontitis (van Winkelhoff et al., 2002). Furthermore, in animal models, subgingival implantation of $P$. gingivalis in mice (Baker 
et al., 1994), primates (Persson et al., 1994) and rats (Evans et al., 1992; Rajapakse et al., 2002) induces periodontal bone loss.

P. gingivalis has a number of putative virulence factors that contribute to its pathogenicity. Among them, the Arg- and Lys-specific cysteine proteinases, designated RgpA and Kgp, respectively, are considered major virulence factors as they have been suggested to play a key role in disease pathogenesis (reviewed by O'Brien-Simpson et al., 2003). RgpA and Kgp are encoded by two genes, namely rgpA and kgp (Curtis et al., 1999). The rgpA gene encodes a polyprotein consisting of an $\mathrm{N}$-terminal preprofragment followed by a $45 \mathrm{kDa}$ Arg-specific, calcium-stabilized cysteine proteinase, $\operatorname{RgpA}_{\mathrm{cat}}$, and four sequence-related adhesin domains: $\operatorname{RgpA}_{\mathrm{A} 1}, \operatorname{RgpA}_{\mathrm{A} 2}, \operatorname{RgpA}_{\mathrm{A} 3}$ and $\mathrm{RgpA}_{\mathrm{A} 4}$ (O'BrienSimpson et al., 2003). Similarly, the kgp gene encodes a polyprotein with a $\mathrm{N}$-terminal preprofragment followed by a $48 \mathrm{kDa}$ Lys-specific cysteine proteinase, $\mathrm{Kgp}_{\text {cat }}$, and five C-terminal adhesin domains: $\mathrm{Kgp}_{\mathrm{A1}}, \mathrm{Kgp}_{\mathrm{A} 2}, \mathrm{Kgp}_{\mathrm{A} 3}$, $\mathrm{Kgp}_{\mathrm{A} 4}$ and $\mathrm{Kgp}_{\mathrm{A} 5}$ (O'Brien-Simpson et al., 2003). Although the proteolytic domains of $r g p A$ and $k g p$ are divergent, with only $25 \%$ identity, their C-terminal adhesin domains share high sequence similarities (Slakeski et al., 1998). In fact, the $\mathrm{A}_{2}$ adhesins $\operatorname{Rgp}_{\mathrm{A} 2}$ and $\mathrm{Kgp}_{\mathrm{A} 2}$ are identical in both gene products (Slakeski et al., 1999).

Depending on the $P$. gingivalis strain, age of culture and purification method, several forms of RgpA and Kgp, both cell-associated and soluble, have been purified and characterized (reviewed by Potempa et al., 2003). The Arg- and Lys-specific proteinases have been purified as monomeric proteins (Bedi \& Williams, 1994; Chen et al., 1992) and as multimeric complexes where the proteinase domains are non-covalently associated with a number of adhesin/ haemagglutinin domains (Bhogal et al., 1997; Pike et al., 1994). Using sonication of exponentially growing $P$. gingivalis W50 cells and three chromatographic procedures, Bhogal et al. (1997) purified and characterized the major cell-associated Arg- and Lys-specific proteinases as a $300 \mathrm{kDa}$ protein complex containing the Arg and Lys proteinases and their associated adhesins. It was proposed that, after the proteolytic processing of the RgpA and Kgp polyproteins into individual domains, they aggregate via adhesin-binding motifs (ABMs) to form the non-covalently associated cell-surface complex designated the RgpA-Kgp proteinase-adhesin complex (Bhogal et al., 1997; Slakeski et al., 1998). Recently, Takii et al. (2005), using sucrose monolaurate to extract $P$. gingivalis cells, confirmed the presence of this proteinase-adhesin complex and its component proteins from RgpA and Kgp, identified by Bhogal et al. (1997), but suggested that it existed as larger aggregates $(660 \mathrm{kDa})$ in the form of $10 \mathrm{~nm}$ diameter particles on the cell surface. However, Takii et al. (2005) used antibodies to recombinant RgpA domains to identify the subunits of the complex and not mass spectrometry. The high sequence similarly of the adhesin domains requires a mass spectrometric approach for definitive identification. Soluble forms of the Arg- and Lys-specific proteinases complexed with adhesin domains have been purified and characterized from culture supernatants, mainly from $P$. gingivalis strain HG66, which reportedly secretes the entire $\operatorname{rgp} A$ and $k g p$ gene products into the culture media (reviewed by Potempa et al., 2003).

The RgpA and Kgp proteinases and their associated adhesins are recognized as major virulence factors for $P$. gingivalis and therefore are of major interest to study in a purified form (Lamont \& Jenkinson, 2000; O’Brien-Simpson et al., 2003). However, the reported methodologies for extracting and purifying RgpA and Kgp as complexes from the cell involve a range of extraction methods and three or more chromatographic purification steps, with many of the purified products being poorly defined. Thus, the major objective of this study was to develop a simple and effective procedure for the extraction and purification of the RgpA and Kgp proteinase-adhesin complexes from $P$. gingivalis cells using Triton X-114 and then to comprehensively characterize the complexes for their subunits using mass spectrometry, as vaccines in an animal model and for their binding properties to a range of host proteins. The non-ionic detergent Triton $\mathrm{X}-114$ was used to extract the complexes as it is a 'mild' detergent that solubilizes membrane-associated proteins while retaining native protein structure (Bordier, 1981) and has been used effectively to extract outer-membrane proteins from a range of bacteria (Brooks et al., 2006; Cullen et al., 2002; Radolf et al., 1988).

\section{METHODS}

Bacterial strains and growth condition. Porphyromonas gingivalis W50 isogenic mutants lacking either the $\operatorname{rgpA}$ gene product (W501) or the kgp gene product (KIA) as well as $P$. gingivalis W50 wild-type were grown in an anaerobic chamber (MK3 anaerobic workstation; Don Whitley Scientific) at $37^{\circ} \mathrm{C}$ on horse blood agar plates supplemented with $10 \%(\mathrm{v} / \mathrm{v})$ lysed horse blood and $10 \mu \mathrm{g}$ erythromycin $\mathrm{ml}^{-1}$ (for the mutant strains). Bacterial colonies were used to inoculate brain heart infusion medium containing $5 \mu \mathrm{g}$ haemin $\mathrm{ml}^{-1}$ and $0.5 \mu \mathrm{g}$ cysteine $\mathrm{ml}^{-1}$. Batch culture growth was monitored at $650 \mathrm{~nm}$ using a spectrophotometer (Perkin-Elmer model 295E). Culture purity was routinely checked by Gram stain, microscopic examination and using a variety of biochemical tests according to Slots (1982).

Extraction of the proteinase-adhesin complexes. $P$. gingivalis strains W50 wild-type, W501 and KIA were grown to late exponential phase (in 21 cultures), harvested by centrifugation $(7500 \mathrm{~g}$, $30 \mathrm{~min}, 4^{\circ} \mathrm{C}$ ) and washed twice with PG buffer $(50 \mathrm{mM}$ Tris/ $\mathrm{HCl}$, $150 \mathrm{mM} \mathrm{NaCl}, 5 \mathrm{mM} \mathrm{CaCl}$ and $5 \mathrm{mM}$ cysteine- $\mathrm{HCl}, \mathrm{pH} 8.0)$ in the anaerobic workstation. Cells were either (1) resuspended in PG buffer, total volume $30 \mathrm{ml}$, containing $0.5 \%(\mathrm{v} / \mathrm{v})$ Triton X114 and gently mixed at room temperature for $45 \mathrm{~min}$ (Triton complex) or (2) resuspended in $30 \mathrm{ml} \mathrm{PG}$ buffer and subjected to mild sonication using a Branson sonifier 250 with an output control of 3 and a $50 \%$ duty cycle (sonication complex). The cell extract was centrifuged $\left(7500 \mathrm{~g}, 30 \mathrm{~min}, 4^{\circ} \mathrm{C}\right)$ and the collected supernatant centrifuged $\left(40000 \mathrm{~g}, 30 \mathrm{~min}, 4^{\circ} \mathrm{C}\right)$. The supernatant was then filtered $(0 \cdot 2 \mu \mathrm{m})$ and the complexes were purified by arginine (Arg)-affinity chromatography. FPLC was performed at room temperature at a flow rate of $1.0 \mathrm{ml} \mathrm{min}{ }^{-1}$. The $P$. gingivalis extracts were applied to 
an Arg-Sepharose column (Hiload XK 16/10 Q, Pharmacia), installed in a Pharmacia GP-250 FPLC system, in TC 50 buffer (buffer A) (50 mM Tris/ $\mathrm{HCl}, 50 \mathrm{mM} \mathrm{NaCl}, 5 \mathrm{mM} \mathrm{CaCl}_{2}, \mathrm{pH} \mathrm{7 \cdot 4}$ ) at a flow rate of $1 \mathrm{ml} \mathrm{min}{ }^{-1}$. Non-specifically bound proteins were eluted with a linear gradient of $0-40 \%$ TC 50 buffer containing, $500 \mathrm{mM} \mathrm{NaCl}, 50 \mathrm{mM}$ Tris/ $\mathrm{HCl}, 5 \mathrm{mM} \mathrm{CaCl}, \mathrm{pH} 7 \cdot 4$ (buffer B) at a flow rate of $1.0 \mathrm{ml} \mathrm{min}{ }^{-1}$. The column was reequilibrated with buffer $\mathrm{A}$ and bound proteins eluted with TC 50 buffer containing $500 \mathrm{mM}$ arginine, $\mathrm{pH} 7 \cdot 4$ at a flow rate of $1 \mathrm{ml} \mathrm{min}^{-1}$. The eluate was monitored at $280 \mathrm{~nm}$. All fractions were collected at $4{ }^{\circ} \mathrm{C}$ and stored at $-70{ }^{\circ} \mathrm{C}$ before further processing.

Arginine-eluted FPLC fractions were concentrated using Vivaspin 20 concentrators (Vivascience) by centrifugation at $3000 \mathrm{~g}$ for $15 \mathrm{~min}$ periods at $4{ }^{\circ} \mathrm{C}$ until the eluate was reduced to a volume of approximately $1 \mathrm{ml}$. The filter membrane of the Vivaspin 20 concentrator was then rinsed with $1 \mathrm{ml}$ TC 50 buffer. Concentrated fractions were then desalted using a PD-10 column (Amersham Pharmacia Biotech), equilibrated with TC 50 buffer and the proteins were eluted with the same buffer as per the manufacturer's instructions.

Arg-specific and Lys-specific proteinase assays. Benzoyl-LArg- $p$-nitroanilide (Bz-L-Arg- $p$ NA) (Sigma) and benzyloxycarbonylL-Lys- $p$-nitroanilide (z-L-Lys- $p \mathrm{NA}$ ) (Novabiochem) were used to assay FPLC fractions for Arg- and Lys-specific proteolytic activity, respectively. Samples of each chromatographic fraction were diluted in TC 50 buffer (total volume $360 \mu \mathrm{l}$ ) and incubated for $10 \mathrm{~min}$ at $37^{\circ} \mathrm{C}$ with $40 \mu \mathrm{l} 100 \mathrm{mM}$ cysteine, $\mathrm{pH}$ 8. After incubation, $400 \mu \mathrm{l}$ of either Bz-L-Arg- $p \mathrm{NA}$ or $\mathrm{z}$-L-Lys- $p \mathrm{NA}$ substrate $(2 \mathrm{mM}$ Bz-L-Arg$p \mathrm{NA}$ or $2 \mathrm{mM}$ z-L-Lys- $p \mathrm{NA}$ ) dissolved in $3 \mathrm{ml}$ propan-2-ol and mixed with $7 \mathrm{ml}$ enzyme buffer $(400 \mathrm{mM}$ Tris/HCl, $100 \mathrm{mM} \mathrm{NaCl}$ and $20 \mathrm{mM}$ cysteine, $\mathrm{pH} 8$ ) was added. The proteolytic activity was determined by measuring the absorbance at $410 \mathrm{~nm}$ for $3 \mathrm{~min}$ at $10 \mathrm{~s}$ intervals using a diode array spectrophotometer model $8452 \mathrm{~A}$ (Hewlett Packard).

Size-exclusion chromatography. This was performed using a macrosphere GPC $300 \AA$ column $(7 \mu \mathrm{m}, 250 \times 4.6 \mathrm{~mm}$, with exclusion limits of 7500-1 200000 Da; Alltech) installed in a Waters Delta 600 HPLC system. Chromatography was performed at a flow rate of $0.5 \mathrm{ml} \mathrm{min}^{-1}$ in $0.05 \mathrm{M} \mathrm{KH} \mathrm{PO}_{4}$ containing $0 \cdot 15 \mathrm{M} \mathrm{Na} \mathrm{Na}_{2} \mathrm{SO}_{4}$ $(\mathrm{pH} 7 \cdot 0)$. Material eluted from the column was detected by determining absorbance at $280 \mathrm{~nm}$. A standard curve of molecular mass gel filtration standards (Amersham Pharmacia Biotech) was used to determine the molecular mass of the eluted fractions.

SDS-PAGE. SDS-PAGE was performed on FPLC fractions by using a Novex electrophoresis system with Novex $12 \%(\mathrm{w} / \mathrm{v})$ Tris/glycine precast mini gels (Invitrogen). Protein samples (10 or $30 \mu \mathrm{g}$ ) were precipitated by addition of trichloroacetic acid (TCA) to a final concentration of $10 \%(\mathrm{v} / \mathrm{v})$ and incubated $20 \mathrm{~min}$ at $4{ }^{\circ} \mathrm{C}$. Precipitated proteins were collected by centrifugation $(10 \mathrm{~min}, 16000 \mathrm{~g})$, resuspended in $20 \mu \mathrm{l}$ reducing sample buffer [10\% (w/v) SDS, $0.05 \%$ $(\mathrm{w} / \mathrm{v})$ bromophenol blue, $25 \%(\mathrm{v} / \mathrm{v})$ glycerol and $0.05 \%(\mathrm{v} / \mathrm{v})$ 2-mercaptoethanol] and the $\mathrm{pH}$ adjusted with the addition of $10 \mu \mathrm{l}$ of $1.5 \mathrm{M}$ Tris $/ \mathrm{HCl}, \mathrm{pH} 8.0$, and then heated for $5 \mathrm{~min}$ at $100^{\circ} \mathrm{C}$. Samples were loaded onto the precast gels and electrophoresis was performed using a current of $30-50 \mathrm{~mA}$ and a potential difference of $125 \mathrm{~V}$. After completion of electrophoresis, the gels were fixed in destain [ $45 \%(\mathrm{v} / \mathrm{v})$ methanol, $10 \%(\mathrm{v} / \mathrm{v})$ acetic acid] for $3 \mathrm{~min}$ at room temperature. For Coomassie blue staining, gels were placed in Coomassie brilliant blue (CBB) $[0 \cdot 1 \%(\mathrm{w} / \mathrm{v})$ CBB R-250, $15 \%(\mathrm{v} / \mathrm{v})$ ethanol, $2 \cdot 5 \%(\mathrm{v} / \mathrm{v})$ acetic acid], heated in a microwave until boiling and then allowed to cool for $5 \mathrm{~min}$. The stain was removed and destain was added and heated in a microwave until boiling and allowed to cool for $5 \mathrm{~min}$. Protein bands were visualized by rinsing gels in Milli Q water overnight.
$\mathbf{N}$-terminal sequence analysis. For sequence analysis, proteins were transferred onto a PVDF membrane (Problott, Applied Biosystems) using a transblot cell (Bio-Rad). The PVDF membrane was wetted in $100 \%$ methanol and soaked in transfer buffer $[10 \mathrm{mM}$ CAPS, $10 \%(\mathrm{v} / \mathrm{v})$ methanol, $\mathrm{pH} \mathrm{11 \cdot 5]} \mathrm{for} 1 \mathrm{~min}$. Transfer was performed using a potential difference of $60 \mathrm{~V}$ for $90 \mathrm{~min}$. Membranes were stained with CBB for $30 \mathrm{~s}$ and destained in $50 \%(\mathrm{v} / \mathrm{v})$ aqueous methanol. Protein bands were excised and N-terminal sequences determined using a Hewlett Packard 10005A protein sequencer as previously described (Bhogal et al., 1997).

In-gel digestion of proteins separated by SDS-PAGE and peptide mass fingerprinting. CBB-stained protein bands from SDS-PAGE were excised and subjected to in-gel trypsin digestion and subsequent peptide extraction. Protein bands were excised from the CBB-stained SDS-PAGE gel and gel pieces were washed in $50 \mathrm{mM} \mathrm{NH}_{4} \mathrm{HCO}_{3} /$ ethanol $1: 1(\mathrm{v} / \mathrm{v})$, reduced and alkylated with DTT and iodoacetamide, respectively, and digested with sequencinggrade modified trypsin $\left(10 \mathrm{ng} \mu \mathrm{l}^{-1}\right)$ (Promega) overnight at $37^{\circ} \mathrm{C}$ as previously published (Mortz et al., 1994). The peptide extract containing $25 \mathrm{mM} \mathrm{NH} \mathrm{HCO}_{3}$ was then analysed by mass spectrometry using an Ultraflex TOF/TOF instrument (Bruker Daltonics) in positive ion and reflectron mode. A saturated solution of 4hydroxy- $\alpha$-cyanocinnamic acid was prepared in $97: 3(\mathrm{v} / \mathrm{v})$ acetone/ $0 \cdot 1 \%$ aqueous trifluoroacetic acid (TFA). A thin layer was prepared by pipetting and immediately removing $2 \mu \mathrm{l}$ of this solution onto the $600 \mu \mathrm{m}$ anchorchips of the target plate. Sample $(0 \cdot 5 \mu \mathrm{l})$ was deposited on the thin layers with $2 \cdot 5 \mu \mathrm{l}$ of $0 \cdot 1 \%(\mathrm{v} / \mathrm{v})$ TFA, and allowed to adsorb for $5 \mathrm{~min}$, after which the sample solution was removed, and the thin layers washed once with $10 \mu$ ice-cold $0 \cdot 1 \%$ (v/v) TFA for $1 \mathrm{~min}$. Spectra were calibrated by close external calibration using a standard peptide mix (Bruker Daltonics). MS/MS spectra were acquired using the 'Lift' technique (Suckau et al., 2003). Proteins were identified by peptide mass fingerprinting (PMF) and MS/MS ions searches against the $P$. gingivalis database (available from http://www.tigr.org) using an in-house Mascot search engine (Matrix Science).

Immunization and mouse lesion model. The mouse lesion model protocols were approved by the University of Melbourne Ethics Committee for Animal Experimentation. BALB/c mice 68 weeks old (10 mice per group) were immunized subcutaneously (s.c., $100 \mu \mathrm{l}$ ) with $25 \mu \mathrm{g}$ complex in phosphate-buffered saline (PBS, $\mathrm{pH} 7 \cdot 4$ ) emulsified in incomplete Freund's adjuvant (IFA). After 30 days, mice were boosted with $25 \mu \mathrm{g}$ antigen (s.c., $100 \mu \mathrm{l}$, emulsified in IFA) and then 12 days later bled from the retrobulbar plexus. Two days after bleeding, mice were challenged with $7 \cdot 5 \times 10^{9}$ viable cells of $P$. gingivalis strain ATCC 33277 by s.c. injection $(100 \mu \mathrm{l})$ in the abdomen, and lesion development measured over 14 days. The $P$. gingivalis inocula were prepared in $\mathrm{PG}$ buffer in the anaerobic workstation as described above. The number of viable cells in the inocula was verified by enumeration on horse blood agar plates. Lesion sizes were statistically analysed using the Kruskal-Wallis test and the Mann-Whitney $U$-Wilcoxon rank sum test with a Bonferroni correction for type 1 error. Effect sizes, represented as Cohen's $d$, were calculated using the effect size calculator provided on-line by Evidence-Based Education UK web site at http://www. cemcentre.org/. According to Cohen (1969) a small effect size is $0 \cdot 2 \leqslant d<0 \cdot 05$, moderate $0 \cdot 5 \leqslant d<0 \cdot 8$ and large $d \geqslant 0 \cdot 8$.

ELISA. ELISAs were performed in triplicate in wells of flat-bottom polyvinyl microtitre plates (Dynatech Laboratories) coated with $10 \mu \mathrm{g} \mathrm{ml}^{-1}$ Triton-wt complex or sonication-wt complex in PBS, $\mathrm{pH} 7 \cdot 4$, overnight at $4{ }^{\circ} \mathrm{C}$. After removal of the coating solution, $2 \%$ $(\mathrm{w} / \mathrm{v})$ skim milk powder in $\mathrm{PBS}, \mathrm{pH} 7 \cdot 4$, containing $0 \cdot 1 \%(\mathrm{v} / \mathrm{v})$ Tween 20 was added to wells to block the uncoated plastic for $1 \mathrm{~h}$ at room temperature. After washing four times with washing buffer [PBS containing $0 \cdot 1 \%(\mathrm{v} / \mathrm{v})$ Tween $20, \mathrm{pH} 7 \cdot 4$ or (PBST)], serial 
dilutions of mouse sera in PBST containing 0.5\% (w/v) skim milk (SK-PBST) were added to each well and incubated for $16 \mathrm{~h}$ at room temperature. After washing six times with PBST, a 1/2000 dilution of goat antisera to mouse IgM, IgA, IgG1, IgG2a, IgG2b, or IgG3 (Sigma) was added in SK-PBST and allowed to bind for $2 \mathrm{~h}$ at room temperature. Plates were washed six times in PBST and a $1 / 5000$ dilution of horseradish peroxidase-conjugated rabbit anti-goat immunoglobulin (Sigma) in SK-PBST was added to each well and incubated for $1 \mathrm{~h}$ at room temperature. After washing (six times, PBST), bound antibody was detected by the addition of $100 \mu \mathrm{l}$ ABTS substrate $[0.9 \mathrm{mM}$ 2,2'-azino-bis (3-ethylbenz-thiazoline-6) sulfonic acid in $80 \mathrm{mM}$ citric acid containing $0.005 \%(\mathrm{v} / \mathrm{v})$ hydrogen peroxide, $\mathrm{pH} 4 \cdot 0$ ] to each well. The $A_{415}$ was measured using a Bio-Rad microplate reader model 450.

Western blot analysis using mouse protective sera. Triton-wt complex and sonication-wt complex $(15 \mu \mathrm{g})$ were subjected to SDSPAGE and electrophoretically transferred onto a PVDF membrane as described above. The PVDF membrane was blocked with skim milk powder in TN buffer $(50 \mathrm{mM}$ Tris/ $\mathrm{HCl}, 100 \mathrm{mM} \mathrm{NaCl}$, $\mathrm{pH} 7 \cdot 4$ ) for $2 \mathrm{~h}$ at room temperature. The membrane was then incubated with anti-wt complex sera at a dilution of $1 / 25$ in TN buffer, overnight at room temperature. After the incubation, the membrane was washed four times in TN buffer containing $0.05 \%$ $(\mathrm{v} / \mathrm{v})$ Tween 20 and incubated with a 1/200 dilution of rabbit antimouse horseradish peroxidase-conjugated IgG (Sigma) for $2 \mathrm{~h}$ at room temperature. The membrane was washed four times with TN buffer containing $0.05 \%(\mathrm{v} / \mathrm{v})$ Tween 20 and the bound antibodies were detected by $0.005 \%(\mathrm{w} / \mathrm{v})$ 4-chloro-1-naphthol in TN buffer containing $16 \cdot 6 \%(\mathrm{v} / \mathrm{v})$ methanol and $0.015 \%(\mathrm{v} / \mathrm{v})$ hydrogen peroxide ( $30 \%$ solution).

Analysis of wt complex, RgpA complex and Kgp complex binding to host proteins. Prior to the ELISA, the proteolytic activity of each proteinase-adhesin complex was inhibited by incu-

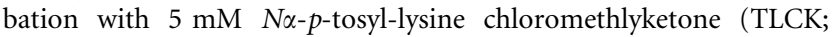
Sigma) for $30 \mathrm{~min}$ at room temperature. Excess TLCK was removed by using a PD-10 column equilibrated with TC 50 buffer with the proteins eluted according to the manufacturer's instructions in the same buffer (Amersham Pharmacia Biotech). ELISAs were performed in triplicate using a solution of $5 \mu \mathrm{g} \mathrm{ml}^{-1}$ of either fibrinogen, fibronectin, collagen type V, laminin or haemoglobin in PBS, $\mathrm{pH} 7 \cdot 4$, to coat wells of flat-bottomed polyvinyl microtitre plates (Microtitre, Dynatech Laboratories) overnight at room temperature. After removing the coating solution, remaining uncoated plastic was blocked with $2 \%(\mathrm{w} / \mathrm{v})$ skim milk powder in PBST for $1 \mathrm{~h}$ at room temperature. After washing $(4 \times \mathrm{PBST})$, equimolar amounts of TLCK-treated Triton-wt complex, sonication-wt complex, RgpA complex or Kgp complex in SK-PBST were added to the wells and incubated at room temperature for $2 \mathrm{~h}$. After washing $(6 \times$ PBST $)$ a $1 / 5000$ dilution of anti-complex sera in SK-PBST was added to each well and incubated $2 \mathrm{~h}$ at room temperature. After washing $(6 \times$ PBST $)$, bound antibody was detected by incubation with a $1 / 5000$ dilution of horseradish peroxidase-conjugated anti-mouse immunoglobulin developed in goat (Sigma) in SK-PBST for $1 \mathrm{~h}$ at room temperature. Wells were then washed $(6 \times$ PBST $)$ and the plates were developed as described above.

ELISA results were used to derive the dissociation equilibrium constant $\left(K_{\mathrm{D}}\right)$ based on an analogue of the Michaelis-Menten equation (Qiu et al., 1996): $A=A_{\max }\left[\right.$ protein] $/ K_{\mathrm{D}}+$ [protein], where $A$ is the absorbance at a given protein concentration, $A_{\max }$ is the maximum absorbance for the ELISA plate reader, [protein] is the protein concentration of the analyte and $K_{\mathrm{D}}$ is the dissociation equilibrium constant for a given absorbance at a given protein concentration (ELISA data point). $K_{\mathrm{D}}$ was calculated by a Scatchard analysis of $1 /$ [protein] vs $1 / K_{\mathrm{D}}$ (ELISA data point): $1 / K_{\mathrm{D}}=m(1 / c)$, where $m$ is the slope of the line and $c$ is the intercept at the $y$ axis, with an $R^{2}$ value $>0.99$.

\section{RESULTS}

\section{Characterization of the proteinase-adhesin complexes extracted using Triton X-114 or sonication and purified by Arg-affinity chromatography}

The proteinase-adhesin complex was extracted from $P$. gingivalis strain W50 using Triton X-114 (Triton-wt complex) and the previously described method of sonication (sonication-wt complex) (Bhogal et al., 1997). Triton $\mathrm{X}-114$ extraction was consistently more effective in releasing cell-surface protein compared with the sonication method, as the Triton X-114 extraction method produced $70 \cdot 0 \pm$ $9 \cdot 2 \mathrm{mg}$ protein from 11 culture. Sonication produced only $10 \cdot 3 \pm 2 \cdot 5 \mathrm{mg}$ protein (Table 1 ). Furthermore, the crude Triton X-114 extract had consistently higher ( threefold) Arg and Lys proteolytic activity compared with the sonication extract (Table 1). The crude Triton X-114 and sonication extracts were subjected to Arg-affinity chromatography and a representative chromatogram is shown in Fig. 1. Non-specifically bound proteins were removed

Table 1. Purification of the wt-complex from Triton and sonication extracts.

\begin{tabular}{|c|c|c|c|c|c|c|c|}
\hline & \multirow{2}{*}{$\begin{array}{c}\text { Total } \\
\text { protein } \\
(\mathbf{m g})\end{array}$} & \multirow{2}{*}{$\begin{array}{l}\text { Arg proteolytic } \\
\text { activity }(\mathbf{U})^{\star}\end{array}$} & \multirow{2}{*}{$\begin{array}{l}\text { Lys proteolytic } \\
\text { activity }(\mathrm{U}) \dagger\end{array}$} & \multirow{2}{*}{$\begin{array}{l}\text { Arg-specific } \\
\text { activity } \\
\left(\mathrm{U} \mathrm{mg}^{-1}\right)\end{array}$} & \multirow{2}{*}{$\begin{array}{l}\text { Lys-specific } \\
\text { activity } \\
\left(\mathrm{U} \mathrm{mg}^{-1}\right)\end{array}$} & \multicolumn{2}{|c|}{ Purification (-fold) } \\
\hline & & & & & & Arg & Lys \\
\hline Crude cell sonicate $\neq$ & $10 \cdot 34 \pm 2 \cdot 52$ & $13 \cdot 60 \pm 2 \cdot 30$ & $1 \cdot 89 \pm 0 \cdot 78$ & $1 \cdot 30 \pm 0 \cdot 62$ & $0 \cdot 18 \pm 0 \cdot 09$ & $1 \cdot 00$ & $1 \cdot 00$ \\
\hline Sonication-wt complex & $0 \cdot 72 \pm 0 \cdot 15$ & $1 \cdot 23 \pm 0 \cdot 24$ & $0 \cdot 09 \pm 0 \cdot 02$ & $1 \cdot 72 \pm 0 \cdot 84$ & $0 \cdot 12 \pm 0 \cdot 06$ & $1 \cdot 32$ & $0 \cdot 69$ \\
\hline Crude Triton X-114 extract $\dagger$ & $70 \cdot 00 \pm 9 \cdot 23$ & $35 \cdot 00 \pm 4 \cdot 32$ & $4 \cdot 56 \pm 1 \cdot 35$ & $0 \cdot 50 \pm 0 \cdot 22$ & $0 \cdot 06 \pm 0 \cdot 01$ & $1 \cdot 00$ & $1 \cdot 00$ \\
\hline Triton-wt complex & $0 \cdot 60 \pm 0 \cdot 12$ & $2 \cdot 45 \pm 0 \cdot 68$ & $1 \cdot 19 \pm 0 \cdot 86$ & $4 \cdot 11 \pm 1 \cdot 24$ & $1 \cdot 97 \pm 0 \cdot 56$ & $8 \cdot 22$ & $32 \cdot 83$ \\
\hline
\end{tabular}

${ }^{\star}$ Amidolytic activity using $2.0 \mathrm{mM} \mathrm{Bz}$-L-Arg- $p$ NA: 1 unit $(\mathrm{U})=1 \mu \mathrm{mol} \mathrm{min}{ }^{-1}$ at $37^{\circ} \mathrm{C}$.

$\dagger$ Amidolytic activity using $2 \cdot 0 \mathrm{mM}$ z-L-Lys-pNA: 1 unit $(\mathrm{U})=1 \mu \mathrm{mol} \mathrm{min}{ }^{-1}$ at $37^{\circ} \mathrm{C}$.

$\ddagger P$. gingivalis W50 Triton X-114 extract or cell sonicate was subjected to FPLC and the proteinase-adhesin complexes purified as described in Methods. 
A

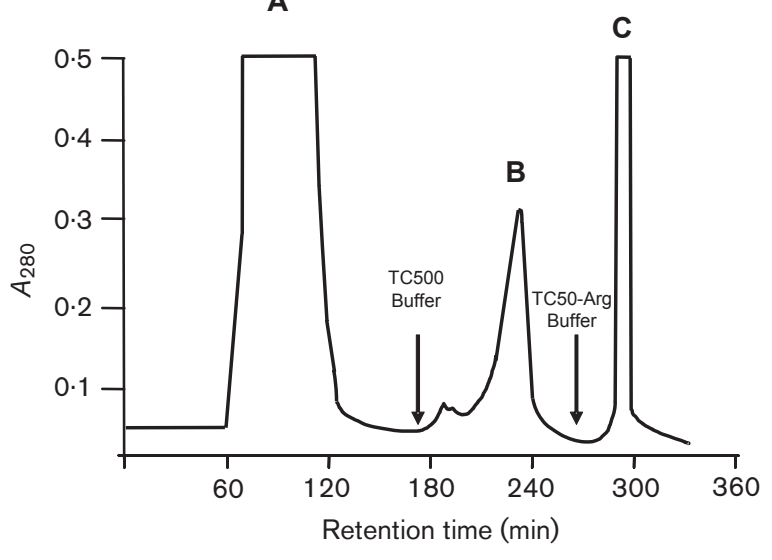

Fig. 1. Typical Arg-Sepharose FPLC chromatogram of $P$. gingivalis TX-114 extract and cell sonication. $P$. gingivalis Triton $\mathrm{X}$ 114 and sonication extracts were applied to an Arg-Sepharose column installed in a Pharmacia FPLC system. Unbound proteins (peak A) were eluted in TC50 buffer at a flow rate of $1 \mathrm{ml} \mathrm{min}{ }^{-1}$. Non-specifically bound proteins (peak B) were eluted with a linear gradient of 0-40\% TC 500 buffer $(500 \mathrm{mM}$ $\mathrm{NaCl}, 50 \mathrm{mM}$ Tris/ $\mathrm{HCl}, 5 \mathrm{mM} \mathrm{CaCl} 2, \mathrm{pH} \mathrm{7.4)}$ at a flow rate of $1.0 \mathrm{ml} \mathrm{min}{ }^{-1}$. The RgpA-Kgp-HagA complex (peak C) was eluted with TC 50-Arg buffer $(500 \mathrm{mM}$ arginine, $50 \mathrm{mM} \mathrm{NaCl}$, $50 \mathrm{mM}$ Tris/ $\mathrm{HCl}, 5 \mathrm{mM} \mathrm{CaCl}, \mathrm{pH} \mathrm{7.4)}$ at a flow rate of $1 \mathrm{ml} \mathrm{min}{ }^{-1}$. The arrows indicate the start of each step gradient.

with a linear gradient of $0-250 \mathrm{mM} \mathrm{NaCl}$ (peak B). The proteinase-adhesin complex was then eluted with $500 \mathrm{mM}$ arginine (peak C) which was collected, concentrated using a VivaSpin-10 concentrator (Sartorius), de-salted using a PD10 column and then subjected to SDS-PAGE. Fig. 2 shows the SDS-PAGE analysis of the $500 \mathrm{mM}$ arginine eluate (peak C) from the Triton X-114 extract (lane 1), with the typical banding pattern associated with the Arg and Lys proteinaseadhesin complex purified using sonication (Bhogal et al., 1997). The N-terminal sequences of the $48,45,44,39,30,17$ and $15 \mathrm{kDa}$ bands of the Triton-wt complex were determined by Edman sequence analysis of electrophoretically transferred proteins onto a PVDF blot (Table 2). This analysis confirmed the presence of the $\mathrm{Kgp}_{\text {cat }}(48 \mathrm{kDa}$ band), $\operatorname{RgpA}_{\text {cat }}$ (45 kDa band), $\operatorname{RgpA}_{\mathrm{A} 1}$ (44 $\mathrm{kDa}$ band), $\mathrm{Kgp}_{\mathrm{A} 1}\left(39 \mathrm{kDa}\right.$ band), $\operatorname{RgpA}_{\mathrm{A} 2} / \mathrm{Kgp}_{\mathrm{A} 2} / \mathrm{HagA}_{\mathrm{A} 2} \quad(17 \mathrm{kDa}$ band) and the $\operatorname{RgpA}_{\mathrm{A} 3}(15 \mathrm{kDa}$ band). The $30 \mathrm{kDa}$ band contained two distinct $\mathrm{N}$-terminal sequences; the predominant sequence was ANEAKVVLAADN, which is consistent with the $\mathrm{N}$-terminal sequences of $\mathrm{RgpA}_{\mathrm{A} 4}$ and $\mathrm{Kgp}_{\mathrm{A} 1}$, and APAPYQER, which is consistent with the N-terminal sequence of $\mathrm{HagA}_{\mathrm{A} 1}{ }^{*}$ (Table 2). To further characterize the proteins in the Triton-wt complex, the protein bands were excised from a Tris-glycine SDS-PAGE gel, trypsin digested and identified by PMF. Protein bands running at approximately 48, 45, 44, 39, 17 and $15 \mathrm{kDa}$ were confirmed as $\operatorname{Kgp}_{\text {cat }}, \operatorname{RgpA}_{\text {cat }}, \operatorname{RgpA}_{\mathrm{A} 1}, \mathrm{Kgp}_{\mathrm{A} 1}, \mathrm{RgpA}_{\mathrm{A} 2} / \mathrm{KgpA}_{\mathrm{A} 2} /$ $\mathrm{HagA}_{\mathrm{A} 2}$ and $\mathrm{RgpA}_{\mathrm{A} 3}$, respectively, by PMF analysis

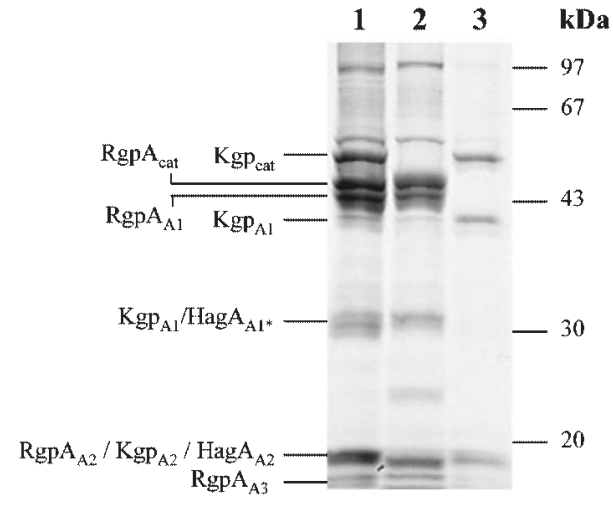

Fig. 2. SDS-PAGE of wt complex, RgpA complex and Kgp complex. The Triton X-114 extracted wt complex, RgpA complex and Kgp complex were subjected to SDS-PAGE and protein bands visualized by Coomassie blue staining. Lanes: 1 , wt complex; 2, RgpA complex; 3, Kgp complex. Molecular mass markers (Pharmacia) are indicated in $\mathrm{kDa}$. Protein bands were transferred onto a PVDF membrane and identified by $\mathrm{N}$-terminal sequence analysis, using a Hewlett Packard 10005A protein sequencer. The designation of each protein band identified by $\mathrm{N}$-terminal sequencing is shown.

(Table 3). The band at $30 \mathrm{kDa}$ was found to consist of two proteins. Seven peptides obtained from the band corresponded to $\mathrm{Kgp}_{\mathrm{A} 1}$ and four obtained corresponded to $\mathrm{HagA}_{\mathrm{A} 1}{ }^{*}$ with the sequence of the $1094.56 \mathrm{Da}$ peptide confirmed by MS/MS fragmentation analysis as the $\mathrm{HagA}_{\mathrm{A} 1}{ }^{*}$ sequence HFGCTGIFR (Table 3 ). In addition, higher molecular mass bands $(55 \mathrm{kDa}$ and $97 \mathrm{kDa})$ were obtained in the SDS-PAGE analysis of the Triton X-114 complex (Fig. 2) that were demonstrated to be partially processed forms of RgpA and Kgp by PMF analysis (data not shown). The Triton X-114 extracted wt complex (Triton-wt complex) had > twofold Arg-specific and >15-fold Lysspecific proteolytic activity compared with the sonicationwt complex (Table 1). N-terminal and PMF analysis of the sonication-wt complex, which produced the same pattern of bands as the Triton-wt complex upon SDS-PAGE, confirmed the presence of the same subunits of the complex except that $\mathrm{HagA}_{\mathrm{A} 1}{ }^{*}$ could not be found in the $30 \mathrm{kDa}$ band. Furthermore, the bands for $\mathrm{Kgp}_{\mathrm{cat}}$ and $\mathrm{RgpA}_{\text {cat }}$ were more intense in the Triton-wt complex, consistent with the higher specific Arg and Lys activity.

\section{Characterization of the Kgp complex and RgpA complex extracted using Triton X-114}

The individual Kgp complex and RgpA complex were purified by Arg-affinity chromatography from Triton X-114 extracts of $P$. gingivalis W50 rgpA mutant (W501) and $\mathrm{kgp}$ mutant (KIA), respectively. Both the Kgp complex and RgpA complex were subjected to SDS-PAGE (Fig. 2), transferred onto a PVDF membrane and N-terminal sequences of the protein bands determined. In the RgpA complex, bands at $45,44,17$ and $15 \mathrm{kDa}$ were identified as $\mathrm{RgpA}_{\text {cat }}$, 
Table 2. N-terminal processing of the Triton-wt complex, RgpA complex and Kgp complex protein domains

Cleavage sites are indicated by vertical arrows.

\begin{tabular}{|c|c|c|c|c|}
\hline \multirow{2}{*}{$\begin{array}{l}\text { Mol. mass (kDa) } \\
\text { determined by } \\
\text { SDS-PAGE }\end{array}$} & \multirow[t]{2}{*}{ Protein domain } & \multicolumn{3}{|c|}{$\mathrm{N}$-terminal sequence } \\
\hline & & Triton-wt complex & RgpA complex & Kgp complex \\
\hline 48 & $\mathrm{Kgp}_{\text {cat }}$ & R-DVYTDHGDLYN- & $-^{*}$ & R-DVYTDHGDLYN- \\
\hline 45 & $\operatorname{RgpA}_{\text {cat }}$ & R-YTPVEEKQNGRM- & R-YTPVEEKQNGRM- & $--^{*}$ \\
\hline 44 & $\operatorname{Rgp}_{\mathrm{A} 1}$ & R-SGQAEIVLEAHDVWN- & R-SGQAEIVLEAHDVWN- & $--^{*}$ \\
\hline 39 & $\operatorname{Kgp}_{\mathrm{A} 1}$ & R-ANEAKVVLAADN- & $-{ }^{*}$ & R-ANEAKVVLAADN- \\
\hline 30 & $\operatorname{Kgp}_{\mathrm{A} 1}$ & R-ANEAKVVLAADN- & $-{ }^{*}$ & $\dagger$ \\
\hline 30 & $\operatorname{HagA}_{\mathrm{A} 1}{ }^{*}$ & K-APAPYQER- & $\dagger$ & $-{ }^{*}$ \\
\hline 17 & $\operatorname{RgpA}_{\mathrm{A} 2} / \operatorname{KgpA}_{2} / \operatorname{HagA}_{\mathrm{A} 2}$ & $\mathrm{R}-$ ADFTETFESSTH- & $\mathrm{R}-$ ADFTETFESSTH- & $\mathrm{R}-$ ADFTETFESSTH- \\
\hline 15 & $\operatorname{RgpA}_{\mathrm{A} 3}$ & K-PQSVWIERT- & R-EADGAKPQSVWIERT- & $-^{*}$ \\
\hline
\end{tabular}

${ }^{*}$ Sequence not present.

$\dagger$ Protein identified by PMF.

$\operatorname{Rgp}_{\mathrm{A} 1}, \operatorname{Rgp}_{\mathrm{A} 2}$ and $\operatorname{RgpA}_{\mathrm{A} 3}$, respectively (Table 2). In the Kgp complex, protein bands at 48, 39 and $17 \mathrm{kDa}$ were identified as $\mathrm{Kgp}_{\mathrm{cat}}, \mathrm{Kgp}_{\mathrm{A} 1}$ and $\mathrm{Kgp}_{\mathrm{A} 2} / \mathrm{HagA}_{\mathrm{A} 2}$, respectively. The band at $30 \mathrm{kDa}$ in the RgpA complex was identified by $\mathrm{PMF}$ analysis as $\mathrm{HagA}_{\mathrm{A1}}{ }^{*}$. The $\mathrm{N}$-terminal sequences of the proteinases and adhesins in the RgpA complex and Kgp complex, with the exception of $\operatorname{RgpA}_{\mathrm{A} 3}$, were the same as found in the wt complex and all were preceded by an arginine residue in the original polyprotein sequence from which they were processed (Table 2). The N-terminal sequence of the $\operatorname{RgpA}_{\mathrm{A} 3}$ adhesin, which in the wt complex is PQSVWIERT, is preceded by a lysine residue, whereas the $\mathrm{N}$-terminus of the $\operatorname{RgpA}_{\mathrm{A} 3}$ adhesin in the RgpA complex extracted from the kgp mutant was extended by six residues, with the sequence EADGAKPQSVWIERT and is preceded by an arginine residue (Table 2 ).

The Arg- and Lys-specific proteinase activities of the purified RgpA complex and Kgp complex were measured. The RgpA complex displayed $1 \cdot 85$ units $\mathrm{mg}^{-1}$ of Arg-specific proteolytic activity but no Lys-specific proteolytic activity (Table 4). The Kgp complex exhibited 0.66 units $\mathrm{mg}^{-1}$ of Lys-specific proteolytic activity and no Arg-specific activity (Table 4).

\section{Size-exclusion chromatography of the wt complex, RgpA complex and Kgp complex}

The purified Triton-wt complex, Kgp complex and RgpA complex were further characterized by size-exclusion chromatography using a Macrosphere $300 \AA$ column (Alltech). The Triton-wt complex eluted as two products, with the major product eluting in the void volume corresponding to a molecular mass of $>1 \cdot 2 \times 10^{6}$ and a second peak eluted at $5 \cdot 63 \mathrm{~min}$ corresponding to a molecular mass of $260 \mathrm{kDa}$ (Fig. 3a). The chromatographic profiles attained for purified Triton-wt complex and sonication-wt complex were similar, with the same retention times and area distribution (data not shown).

The RgpA complex eluted as two products, with the major product eluting in the void volume corresponding to high molecular mass of $>1 \cdot 2 \times 10^{6}$ and a second peak eluted at $5.68 \mathrm{~min}$ corresponding to a molecular mass of approximately 150 kDa (Fig. 3b). Similarly, the Kgp complex eluted as two products, with the major product eluting in the void volume corresponding to a molecular mass of $>1.2 \times 10^{6}$ and a second peak eluted at $5.69 \mathrm{~min}$ corresponding to a molecular mass of approximately $120 \mathrm{kDa}$ (Fig. 3c).

\section{Immunogenicity of the wt complex}

To characterize the immunogenicity of the Triton-wt complex and the sonication-wt complex, BALB/c mice were immunized (day 0 and day 30) with either sonication-wt complex or Triton-wt complex emulsified in incomplete IFA or with adjuvant alone. Twelve days after the second immunization, mice were challenged subcutaneously with P. gingivalis strain ATCC 33277. The development of lesions was monitored for the next 14 days for each group. Fig. 4 shows that the mean lesion size of mice immunized with purified Triton-wt complex or sonication-wt complex was significantly $(P<0 \cdot 01 ; P<0 \cdot 05$, respectively) smaller than that of the PBS/IFA control group. The Triton-wt complex, when used as a vaccine, tended to be more effective $(d=1 \cdot 85,99 \% \mathrm{CI}: 3 \cdot 07,0 \cdot 47)$ in providing protection as indicated by a larger effect size compared with the sonication-wt complex $(d=1 \cdot 32,95 \% \mathrm{CI}: 2 \cdot 28,0 \cdot 07)$. 
Table 3. Peptide mass fingerprinting identification of the proteins in the Arg-affinity purified Triton X114 extracted wt complex

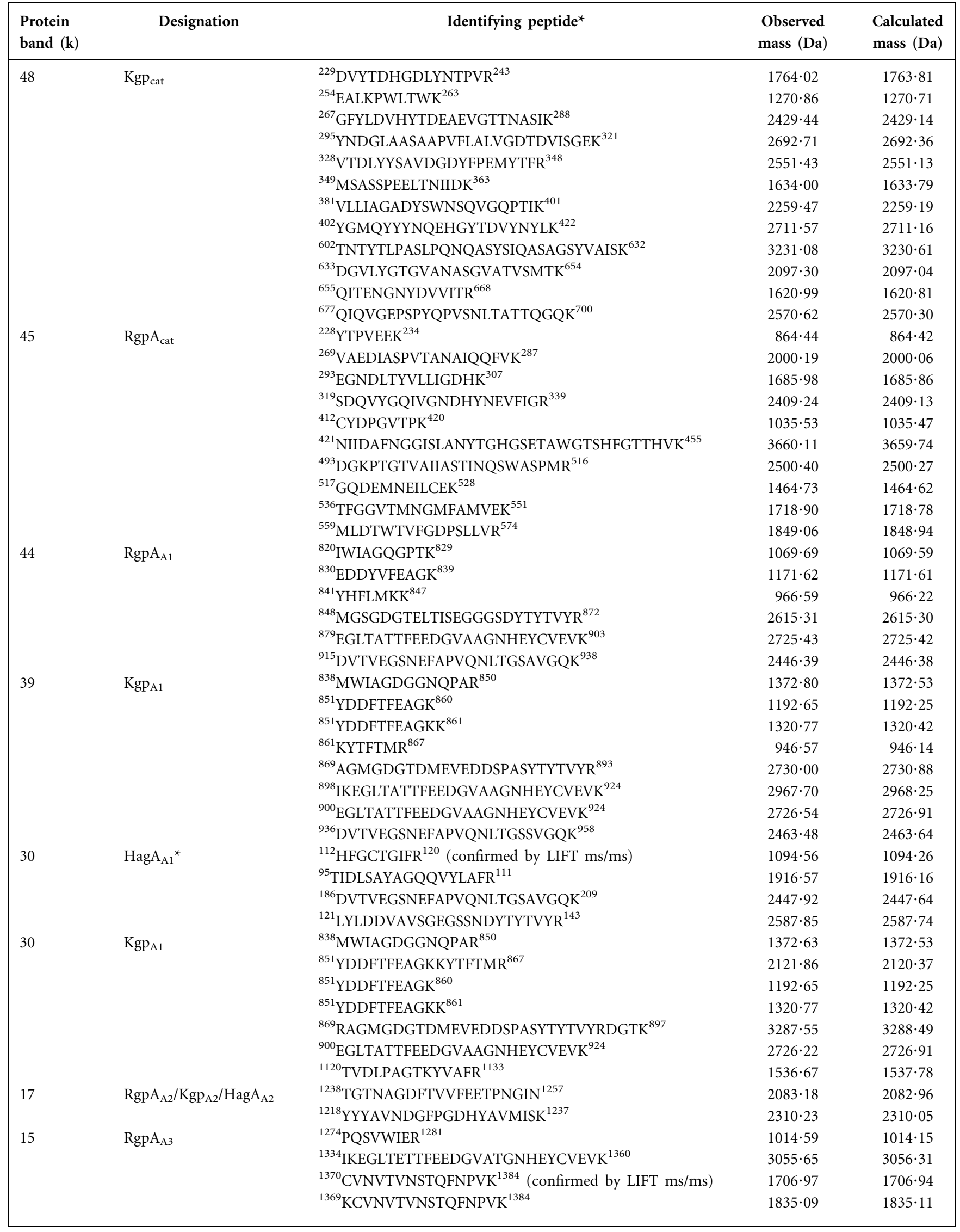

Peptide fragments confirmed by PMF. 
Table 4. Purification of the RgpA complex and Kgp complex

\begin{tabular}{|c|c|c|c|c|c|c|c|}
\hline & \multirow{2}{*}{$\begin{array}{c}\text { Total } \\
\text { protein } \\
(\mathbf{m g})\end{array}$} & \multirow{2}{*}{$\begin{array}{l}\text { Arg proteolytic } \\
\text { activity }(\mathbf{U})^{\star}\end{array}$} & \multirow{2}{*}{$\begin{array}{l}\text { Lys proteolytic } \\
\text { activity }(\mathrm{U}) \dagger\end{array}$} & \multirow{2}{*}{$\begin{array}{l}\text { Arg-specific } \\
\text { activity } \\
\left(\mathrm{U} \mathrm{mg}^{-1}\right)\end{array}$} & \multirow{2}{*}{$\begin{array}{c}\text { Lys-specific } \\
\text { activity } \\
\left(\mathrm{U} \mathrm{mg}^{-1}\right)\end{array}$} & \multicolumn{2}{|c|}{ Purification (-fold) } \\
\hline & & & & & & Arg & Lys \\
\hline Crude $k g p$ mutant Triton extract $\ddagger$ & $57 \cdot 9 \pm 5 \cdot 95$ & $71 \cdot 40 \pm 9 \cdot 40$ & 0 & $1 \cdot 23 \pm 0 \cdot 19$ & 0 & $1 \cdot 00$ & 0 \\
\hline $\begin{array}{l}\text { RgpA complex purified from the } \\
\text { kgp mutant }\end{array}$ & $2 \cdot 54 \pm 0 \cdot 56$ & $4 \cdot 68 \pm 1 \cdot 89$ & 0 & $1 \cdot 85 \pm 0 \cdot 89$ & 0 & $1 \cdot 50$ & - \\
\hline Crude $\operatorname{rgp} A$ mutant Triton extract $\ddagger$ & $40 \cdot 2 \pm 8 \cdot 60$ & $10 \cdot 20 \pm 2 \cdot 40$ & $6 \cdot 00 \pm 1 \cdot 40$ & $0 \cdot 26 \pm 0 \cdot 04$ & $0 \cdot 16 \pm 0 \cdot 09$ & - & $1 \cdot 00$ \\
\hline $\begin{array}{l}\text { Kgp complex purified from the } \\
\text { rgpA mutant }\end{array}$ & $1 \cdot 11 \pm 0 \cdot 63$ & 0 & $0 \cdot 73 \pm 0.09$ & 0 & $0 \cdot 66 \pm 0 \cdot 23$ & - & $4 \cdot 13$ \\
\hline
\end{tabular}

${ }^{\star}$ Amidolytic activity using $2 \cdot 0 \mathrm{mM} \mathrm{Bz-L-Arg}$ - $p \mathrm{NA}: 1$ unit $(\mathrm{U})=1 \mu \mathrm{mol} \mathrm{min}{ }^{-1}$ at $37^{\circ} \mathrm{C}$.

$\dagger$ Amidolytic activity using $2 \cdot 0 \mathrm{mM} \mathrm{z}$-L-Lys- $p \mathrm{NA}: 1$ unit $(\mathrm{U})=1 \mu \mathrm{mol} \mathrm{min}{ }^{-1}$ at $37^{\circ} \mathrm{C}$.

$\ddagger P$. gingivalis $k g p$ mutant and $r g p A$ mutant crude extracts were prepared as described in Methods.
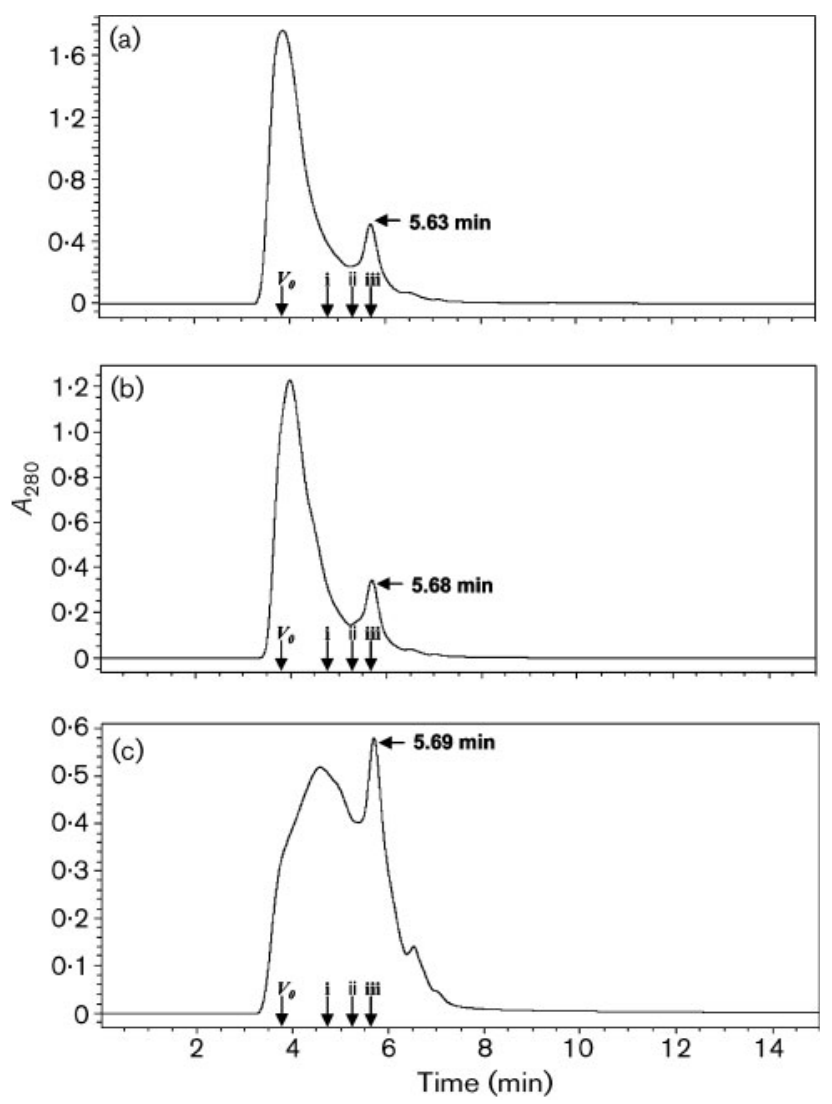

Fig. 3. Gel filtration chromatography of the Triton-wt complex, RgpA complex and Kgp complex. Arginine-affinity purified Triton X-114 extracted wt complex (a), RgpA complex (b) and Kgp complex (c) were applied to a size-exclusion column (macrosphere $300 \AA, 7 \mu \mathrm{m}, 250 \times 4.6 \mathrm{~mm}$, Alltech) installed in a Waters Delta 600 HPLC system and the chromatogram developed at a flow rate of $0.5 \mathrm{ml} \mathrm{min}{ }^{-1}$ in $0.05 \mathrm{M} \mathrm{KH}_{2} \mathrm{PO}_{4}$ containing $0.15 \mathrm{M} \mathrm{Na}_{2} \mathrm{SO}_{4}, \mathrm{pH} 7 \cdot 0$. The column eluate was monitored at $280 \mathrm{~nm}$ to detect tryptophan and tyrosine residues. $V_{0}$ indicates the void volume of the column. The elution volumes of the standard proteins - i, thyroglobulin (669 kDa); ii, ferritin $(312 \mathrm{kDa})$; iii, catalase $(232 \mathrm{kDa})$ - are marked.
Moreover, only $50 \%$ of the mice immunized with the Triton-wt complex developed $P$. gingivalis-induced lesions, whereas $70 \%$ of the mice immunized with the sonication-wt complex developed lesions.

The subclass antibody response induced by the wt complex was determined by ELISA. The results, shown in Fig. 5, demonstrate that immunization with the Triton-wt complex elicited a higher antibody titre compared with the sonication-wt complex. The Triton-wt complex induced higher levels of IgG, IgG1, IgG2a, IgG2b and IgG3 antibodies, with the predominant antibody subclass being IgG1.

Western blot analysis of the Triton-wt complex and sonication-wt complex was performed using protective

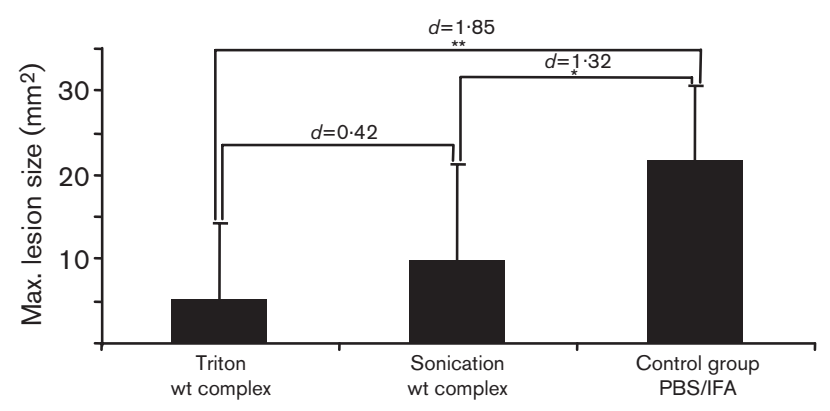

Fig. 4. Maximum lesion size of mice immunized with wt complex extracted by sonication or by Triton X-114. BALB/C mice (10 mice per group) were immunized s.c. with Triton complex or sonication complex (emulsified in incomplete Freund's adjuvant, $25 \mu \mathrm{g}$ per mouse) for the primary (day 0) and secondary (day 30 ) immunizations and challenged s.c. (day 42) with $P$. gingivalis ATCC $33277\left(7.5 \times 10^{9}\right.$ viable cells). Animals were monitored over a period of 14 days for the development and size of lesions. Lesion sizes were statistically analysed using the KruskalWallis test and the Mann-Whitney U-Wilcoxon rank sum test with a Bonferroni correction for type 1 error and effect size (Cohen's $d$ ). ${ }^{*},{ }^{* *}$ group significantly different $(P<0.05, P<0.01$, respectively $)$ from the control (PBS/IFA) group. 


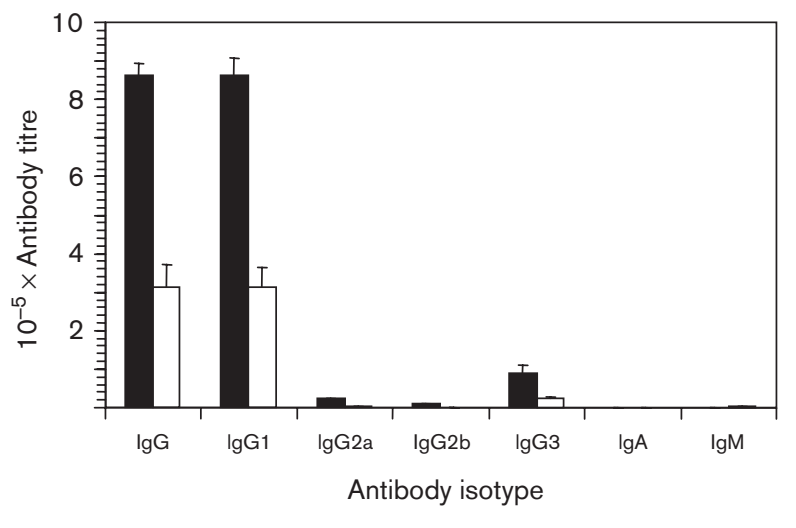

Fig. 5. Serum antibody subclass responses to the wt complexes extracted using the Triton X-114 and sonication procedures. Sera from mice immunized with the Triton-wt complex (black bars) and sonication complex (white bars) were used in the ELISA with the complex as the absorbed antigen. Antibody responses are expressed as the ELISA titre determined as the reciprocal of the dilution at which absorbance was double the background level, with each titre representing the mean $\pm S D$ of three values.

anti-complex mouse sera. The Triton-wt complex antisera exhibited strong immunoreactive bands at molecular masses 44,39 and $30 \mathrm{kDa}$, corresponding to the $\operatorname{Rgp}_{\mathrm{A} 1}, \mathrm{Kgp}_{\mathrm{A} 1}$ and $\mathrm{HagA}_{\mathrm{A} 1}{ }^{\star}$ adhesins (Fig. 6). The sonication-wt complex also displayed immunoreactive bands of molecular masses 44 and $39 \mathrm{kDa}$, corresponding to the complex proteins $\mathrm{RgpA}_{\mathrm{A} 1}$ and $\mathrm{Kgp}_{\mathrm{A} 1}$ (Fig. 6). The immunoreactive $45 \mathrm{kDa}$ band of the wt complex was found not to be $\operatorname{RgpA}_{\text {cat }}$, as the complex antisera did not recognize $\mathrm{RgpB}$, which has $97 \%$ sequence identity to the RgpA proteinase, suggesting that the immunoreactive band detected at $45 \mathrm{kDa}$ was also derived from the adhesins (data not shown). These data suggest that the Trion wt complex produces a stronger antibody response directed towards the Al adhesins of RgpA, Kgp

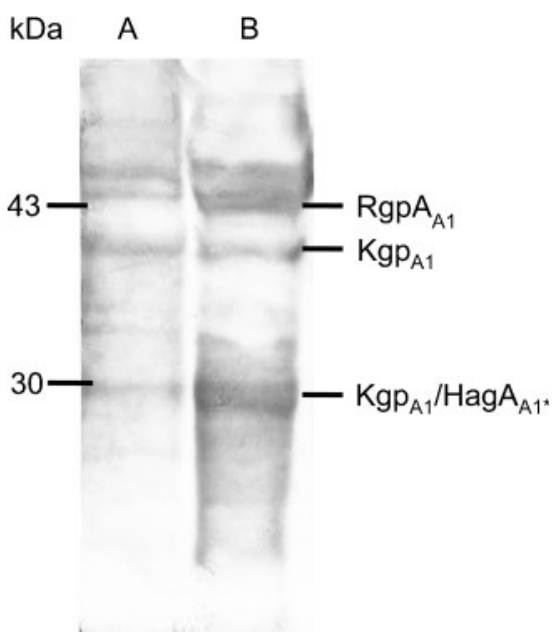

Fig. 6. Western blot analysis of the wt complex probed with antisera from mice immunized with the sonication-wt complex (A) or Triton-wt complex (B). The Triton-wt complex and sonication-wt complex were separated by SDS-PAGE, transferred onto PVDF membrane and probed with Triton-wt complex (1:50 TN buffer) and sonication-wt complex antisera (1:50 TN buffer), respectively. Molecular mass markers are shown in $\mathrm{kDa}$.

and HagA polyproteins compared with the sonication-wt complex.

\section{$K_{\mathrm{D}}$ for the binding of the wt complex, RgpA complex and Kgp complex to host proteins}

The binding of purified Triton-wt complex, sonication-wt complex, RgpA complex and Kgp complex to fibrinogen, fibronectin, haemoglobin, laminin, and collagen types I, III, IV and $\mathrm{V}$ was determined by ELISA. $K_{\mathrm{D}}$ for each interaction was determined by Scatchard analysis of the ELISA data (Table 5). The Triton-wt complex bound in the nanomolar and subnanomolar range to the proteins tested, with the strongest binding to fibrinogen followed by fibronectin,

Table 5. Equilibrium constants $\left(K_{\mathrm{D}}\right)$ for binding of the wt complex, RgpA complex and Kgp complex to host proteins

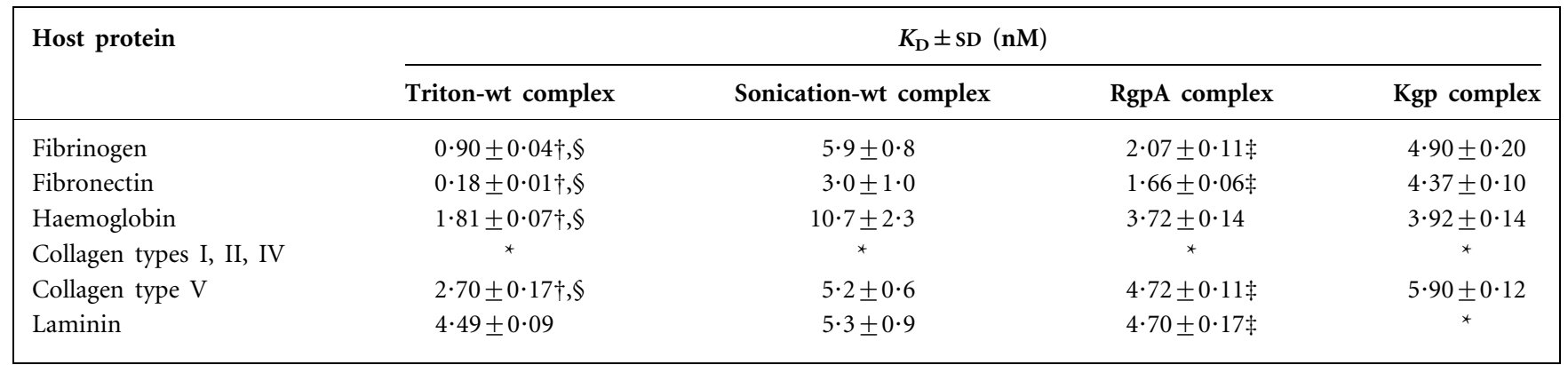

${ }^{\star}$ Binding not detected.

$\dagger$ Significantly $(P<0 \cdot 01)$ different to sonication-wt complex.

$¥$ Significantly $(P<0 \cdot 01)$ different to Kgp complex.

$\S$ Significantly $(\mathrm{P}<0 \cdot 01)$ different to Kgp complex and RgpA complex. 
haemoglobin, collagen type $\mathrm{V}$ and laminin, but no binding was detected for collagen types I, III and IV. Although the sonication-wt complex also bound to host proteins in the nanomolar range, the Triton-wt complex was significantly $(P<0 \cdot 01)$ more effective at binding to fibrinogen $(d=$ $-6 \cdot 25,99 \%$ CI: $-12 \cdot 69,-1 \cdot 4)$, fibronectin $(d=-2 \cdot 82$, $99 \%$ CI: $-6 \cdot 35,-0 \cdot 02)$, haemoglobin $(d=-3 \cdot 87,99 \%$ CI: $-8 \cdot 22,-0 \cdot 5)$ and collagen type $\mathrm{V}(d=-4 \cdot 17,99 \% \mathrm{CI}$ : $-8 \cdot 49,-0 \cdot 56)$. The individual Kgp complex and RgpA complex had significantly $(P<0 \cdot 01)$ lower binding affinities to all the proteins tested with the exception of laminin (Table 5). Although, the Kgp complex had binding affinities in the nanomolar range, it exhibited significantly $(P<0 \cdot 01)$ weaker binding to fibrinogen, fibronectin and collagen type $\mathrm{V}$ compared with the Triton-wt complex and RgpA complex (Table 5). Furthermore, the Kgp complex, unlike the wt complex and the RgpA complex, did not bind to laminin (Table 5). Both the Kgp complex and RgpA complex had similar binding affinities to haemoglobin (Table 5).

\section{DISCUSSION}

The Arg- and Lys-specific proteinases and their associated adhesins (proteinase-adhesin complexes) are major virulence factors of $P$. gingivalis (O'Brien-Simpson et al., 2004). In this study, we describe a simple method of extraction and purification of the major cell-asscoiated proteinase-adhesin complexes from $P$. gingivalis using Triton X-114 and a single Arg-affinity chromatography procedure. Although other authors have used detergents such as CHAPS or Triton $\mathrm{X}-100$ in the extraction step for the proteinase-adhesin complexes from $P$. gingivalis, these detergents were used to solubilize proteins after sonication (Fujimura et al., 1998; Kontani et al., 1996). Takii et al. (2005) used sucrosemonolaurate to extract outer-membrane proteins from $P$. gingivalis, but as with all other reports these authors used multiple chromatography procedures to purify the proteinase-adhesin complexes. Furthermore, Takii et al. (2005) did not characterize their purified complex using mass spectrometry. The Triton X-114 extraction method described here was significantly more effective than the previously described sonication method for the extraction of the proteinase-adhesin complexes from the cell surface, as demonstrated by a higher yield and the presence of substantially more Arg- and Lys-specific proteolytic activity. Interestingly, the Lys-specific activity of the Triton-wt complex was comparable to the Lys-specific activity of the Kgp proteinase-adhesin complex purified from culture supernatants of $P$. gingivalis strain HG66 by Pike et al. (1994). The higher specific Arg and Lys proteolytic activity of the Triton-wt complex and the presence of the $\mathrm{HagA}_{\mathrm{A} 1}{ }^{*}$ domain are consistent with the Triton X-114 procedure extracting and retaining the native structure of the complex better than the sonication procedure.

Using $\mathrm{N}$-terminal sequence analysis and peptide mass fingerprinting, the extracted and purified Triton-wt complex was found to contain $\operatorname{RgpA}_{\text {cat }}, \operatorname{RgpA}_{\mathrm{A} 1}, \operatorname{RgpA}_{\mathrm{A} 2}$,
$\mathrm{RgpA}_{\mathrm{A} 3}, \mathrm{Kgp}_{\mathrm{cat}}, \mathrm{Kgp}_{\mathrm{A} 1}, \mathrm{Kgp}_{\mathrm{A} 2}, \mathrm{HagA}_{\mathrm{A} 2}$ and $\operatorname{HagA}_{\mathrm{A} 1}$, corresponding to the molecular masses, as determined by SDS-PAGE and deduced from the gene sequence (Veith et al., 2002) in parentheses of 45 (51), 44 (38), 17 (13), 15 (15), 48 (53), 39 (38), 17 (13), 17 (13) and 30 (28), respectively, which equates to the Triton-wt complex having a combined molecular mass of $272(262) \mathrm{kDa}$, assuming stoichiometric amounts of each domain. This molecular mass is very similar to the relative molecular mass $(260 \mathrm{kDa})$ of the smaller molecular mass peak of the Triton-wt complex determined by size-exclusion chromatography. However, the majority of the purified proteinase-adhesin complexes eluted in the void volume of the size-exclusion column, suggesting that the individual complexes may form larger aggregates on the cell surface as suggested by Takii et al. (2005) or that the complexes further aggregate after they are released/extracted from the cell surface. Furthermore, for both the Kgp complex and RgpA complex, gel filtration peaks that correspond to the relative molecular masses of $120 \mathrm{kDa}$ and $150 \mathrm{kDa}$, respectively, fitted well with the stoichiometric amounts of the domains identified for each complex; Kgp $\mathrm{Kat}_{\mathrm{cat}} 48$ (53), $\mathrm{Kgp}_{\mathrm{A} 1} 39$ (38), $\mathrm{Kgp}_{\mathrm{A} 2} 17$ (13) and $\mathrm{Hag}_{\mathrm{A} 2} 17$ (13) producing 121 (117) $\mathrm{kDa}$ and $\mathrm{RgpA}_{\text {cat }} 45$ (51), $\operatorname{RgpA}_{\mathrm{A} 1} 44$ (38), $\operatorname{RgpA}_{\mathrm{A} 2} 17$ (13), $\operatorname{RgpA}_{\mathrm{A} 3} 15$ (15) and $\mathrm{HagA}_{\mathrm{A} 1}{ }^{*} 30$ (28) producing 151 (145) $\mathrm{kDa}$, respectively.

The N-terminal sequence and cleavage sites of the protein domains from the Triton-Kgp complex and Triton-RgpA complex were compared with the corresponding domains of the Triton-wt complex. The N-terminal sequence and cleavage sites of $\mathrm{Kgp}_{\mathrm{cat}}, \mathrm{Kgp}_{\mathrm{A} 1}$ and $\mathrm{Kgp}_{\mathrm{A} 2}$ from the $P$. gingivalis rgpA mutant and $P$. gingivalis W50 (wild-type) were identical, with an Arg residue preceding all the cleavage sites. This indicates that in the absence of RgpA proteinase activity, the N-terminal processing of $\mathrm{Kgp}_{\mathrm{cat}}, \mathrm{Kgp}_{\mathrm{A} 1}$ and $\mathrm{Kgp}_{\mathrm{A} 2}$ domains of the Kgp complex is performed by another Arg-X proteinase, probably RgpB. Recently, Veith et al. (2002) demonstrated that either RgpA or RgpB proteinase activity had a role in the $\mathrm{N}$-terminal processing of $\mathrm{Kgp}$ proteins, where the $\mathrm{N}$-termini of $\mathrm{Kgp}_{\mathrm{cat}}, \mathrm{Kgp}_{\mathrm{A} 1}$ and $\mathrm{Kgp}_{\mathrm{A} 2}$ from an outer-membrane preparation of a $\operatorname{rgp} A / \mathrm{rgp} B$ double mutant had extended and often ragged $\mathrm{N}$-termini. Similarly, $\operatorname{RgpA}_{\text {cat }}, \operatorname{RgpA}_{\mathrm{A} 1}$ and $\mathrm{RgpA}_{\mathrm{A} 2}$ domains, but not the $\mathrm{RgpA}_{\mathrm{A} 3}$ adhesin domain, from the $P$. gingivalis $\mathrm{kg} P$ mutant and $P$. gingivalis W50 (wild-type) had identical $\mathrm{N}$-termini with an Arg residue preceding the cleavage site, consistent with either RgpA and/or RgpB proteolytic activity being involved in the processing of these domains. The $\mathrm{RgpA}_{\mathrm{A} 3}$ adhesin domain from $P$. gingivalis W50 (wild-type) is preceded by a lysine residue, and the $\mathrm{RgpA}_{\mathrm{A} 3}$ adhesin of the RgpA complex extracted from the $P$. gingivalis $\mathrm{kg} p$ mutant was extended by six residues and was preceded by an arginine residue. This suggests that the Kgp proteinase normally participates in the proteolytic processing of the $\mathrm{RgpA}_{\mathrm{A} 3}$ domain in wild-type $P$. gingivalis and that in the absence of the Kgp proteinase, either RgpA or RgpB proteinase processes the $\mathrm{RgpA}_{\mathrm{A} 3}$ adhesin. 
The processing of RgpA and Kgp polypeptides into fully active mature proteins on the cell surface is not yet fully understood. Recently, Mikolajczyk et al. (2003) reported a possible activation pathway for RgpB, which involves the removal of $\mathrm{N}$ - and $\mathrm{C}$-terminal extensions in three sequential autoproteolytic steps to generate fully active RgpB. Similarly, it has been suggested that prior to becoming fully processed and active proteins on the cell surface, the RgpA or Kgp polypeptides undergo a succession of proteolytic cleavages and these proteolytically processed domains become tightly associated and form the RgpA-Kgp proteinase-adhesin complex on the cell surface (Bhogal et al., 1997). The $\mathrm{N}$-terminal sequencing and PMF data shown in the present study demonstrate that the Kgp proteinase is involved in processing of the $\mathrm{RgpA}_{\mathrm{A} 3}$ adhesin domain and the majority of the RgpA and Kgp domains are processed by either the RgpA or RgpB proteinases. Using proteinase inhibitors to eliminate proteolytic processing during extraction, Veith et al. (2002) showed that the RgpA and Kgp proteinase and adhesins are fully processed domains on the cell surface of $P$. gingivalis. Our data suggest that processed domains of the three polyproteins RgpA, Kgp and HagA combine noncovalently to form complexes either on the cell surface or immediately upon release from the cell surface.

It is interesting that in this study the C-terminal domains of both RgpA and Kgp were not found in the extracted complexes. RgpA-Kgp complexes characterized by Pike et al. (1994) and Bhogal et al. (1997) were reported to contain the C-terminal domain $\operatorname{RgpA}_{\mathrm{A} 4}$ as a $27-30 \mathrm{kDa}$ protein based on SDS-PAGE. Both Pike et al. (1994) and Bhogal et al. (1997) used N-terminal sequence analysis to identify $\operatorname{RgpA}_{\mathrm{A} 4}$. However, in the current study we used PMF analysis, which conclusively identified the protein domains in the $30 \mathrm{kDa}$ band of the RgpA-Kgp complexes as $\mathrm{Kgp}_{\mathrm{Al}} /$ $\operatorname{HagA}_{\mathrm{A} 1}{ }^{*} \cdot \mathrm{Kgp}_{\mathrm{A} 1}$ has an identical N-terminal sequence to $\mathrm{RgpA}_{\mathrm{A} 4}$, which would explain why Pike et al. (1994) and Bhogal et al. (1997) both assigned this band to $\operatorname{RgpA}_{\mathrm{A} 4}$. The pattern of protein bands obtained by SDS-PAGE analysis of the RgpA-Kgp complexes purified by Pike et al. (1994) and Bhogal et al. (1997) were the same as those obtained in this study with the Triton-wt complex, where PMF analysis confirmed the absence of the C-terminal domains of both RgpA and Kgp in the purified complex. Veith et al. (2002) showed using 2D-PAGE analysis of $P$. gingivalis W50 outer membranes that the C-terminal domain of RgpA, $\operatorname{RgpA}_{\mathrm{A} 4}$ was present as a highly post-translationally modified form that reacted with $\mathrm{mAb} 1 \mathrm{~B} 5$ whereas the other RgpA and Kgp domains obtained did not react with the mAb. This $\mathrm{mAb}$ has recently been reported to react with a phosphorylated branched mannan that has been suggested to be part of the outermost layer of the $P$. gingivalis cell wall (Paramonov et al., 2005). These results together suggest that the C-terminal domain of $\mathrm{RgpA}_{\mathrm{A} 4}$ may be attached to the cell wall and hence may serve to anchor the complex to the cell. Treatment of the cell with Triton X-114 may have dissociated the RgpA-Kgp complex from its C-terminal anchor or may have triggered proteolytic processing, releasing the complex from the attached C-terminal domain.

As RgpA and Kgp are reported to be major virulence factors of $P$. gingivalis (reviewed by O'Brien-Simpson et al., 2004), we evaluated the protective efficacy of the complexes as vaccines in the murine lesion model. Both the Triton-wt complex and sonication-wt complex provided protection against challenge with $P$. gingivalis. However, the Triton-wt complex, when used as a vaccine, tended to be more effective in providing protection (as indicated by a larger effect size) compared with the sonication-wt complex. Moreover, immunization with Triton-wt complex induced higher levels of IgG, IgG1, IgG2a, IgG2b and IgG3 antibodies compared with the sonication-wt complex. The predominant antibody subclass induced was IgG1 (equivalent to IgG4 in humans), which is a Th2 cytokine-induced antibody that has previously been shown to be involved in a protective immune response against $P$. gingivalis-induced lesions in the mouse (O'Brien-Simpson et al., 2000). Furthermore, Western blot analysis suggested that antibodies to the Triton-wt complex bound strongly to $\operatorname{RgpA}_{\mathrm{A} 1}, \mathrm{Kgp}_{\mathrm{A} 1}$ and $\mathrm{HagA}_{\mathrm{A1}}{ }^{*}$ adhesins, whereas antibodies to the sonication-wt complex bound to $\mathrm{RgpA}_{\mathrm{A} 1}$ and $\mathrm{Kgp}_{\mathrm{A} 1}$. These data suggest that the complex extracted using the Triton X-114 method produces a strong antibody response directed towards the $\mathrm{A} 1$ adhesins of RgpA, Kgp and HagA. The RgpA $\mathrm{Al}_{1}, \mathrm{Kgp}_{\mathrm{A} 1}$ and $\mathrm{HagA}_{\mathrm{A} 1}{ }^{*}$ adhesins share a high degree of sequence similarity and interestingly, each contain the previously described protective peptide epitopes ABM1, ABM2 and ABM3 (O'Brien-Simpson et al., 2000). Taken together, our results suggest that proteinase-adhesin complexes extracted from $P$. gingivalis are composed of processed domains of all three polyproteins, RgpA, Kgp and HagA, and that the superiority of the Triton X-114-extracted complex in protection may relate to the Triton complex more closely resembling the form of the proteins on the cell surface.

Binding studies demonstrated that the Triton-wt complex, sonication-wt complex, RgpA complex and Kgp complex bind at nanomolar levels to fibrinogen, fibronectin, collagen type $\mathrm{V}$ and haemoglobin. Interestingly, the Triton-wt complex demonstrated a higher affinity to all the proteins tested compared with the sonication-wt complex. The RgpA complex exhibited higher binding for all the proteins tested compared with the Kgp complex with the exception of binding to haemoglobin, where the $K_{\mathrm{D}}$ for each complex was similar. In an earlier study, Pike et al. (1996) reported that the RgpA complex and Kgp complex purified from the culture supernatant of $P$. gingivalis strain HG66 bound to fibrinogen, fibronectin and laminin. The $K_{\mathrm{D}}$ of binding to fibrinogen was reported to be $8.5 \mathrm{nM}$ and $4.0 \mathrm{nM}$ for the RgpA complex and Kgp complex, respectively. This $K_{\mathrm{D}}$ of binding to fibrinogen is in good agreement with our findings, where the $K_{\mathrm{D}}$ of the Kgp complex binding to fibrinogen was $4 \cdot 9 \pm 0 \cdot 2 \mathrm{nM}$. However, in the present study the RgpA complex had a stronger binding to fibrinogen, with a $K_{\mathrm{D}}$ of $2 \cdot 07 \pm 0 \cdot 11 \mathrm{nM}$. This could be due to differences in strain, 
age of culture and purification method used between the two studies. Knibbs et al. (1998) reported that the affinity of a protein to its ligand can be enhanced with an increase in ligand valency. Therefore, the higher binding to host proteins of the Triton-wt complex and RgpA complex compared with the Kgp complex may be due to the valency of ABMs in each complex. O'Brien-Simpson et al. (2005) have shown that antibodies directed to ABM2 (SYTYTVYRDGTKIKEGLTATTFEEDGVAA) block binding of the complex to fibrinogen, fibronectin and collagen type $\mathrm{V}$, and antibodies to ABM3 (VTLKWDAPNGTPNPNPNPNPNPNPGTTTLSESF) block binding to haemoglobin. ABM2 is repeated three times in the adhesin domains of the RgpA complex and twice in the adhesin domains of Kgp complex, whereas ABM3 is repeated only once in the RgpA complex and Kgp complex. Thus, the stronger binding of the RgpA complex to fibrinogen, fibronectin and collagen type $V$ may be due to the presence of a greater number of ABM2 sequences in its adhesin domains. In contrast, the similar levels of binding to haemoglobin observed with both the RgpA and Kgp complex may be explained by the presence of the same number of ABM3 sequences in their adhesin domains. The Triton-wt complex, which has the highest valency of $A B M 2$ and $A B M 3$ sequences, was found to have the strongest levels of binding to all the proteins tested. However, the higher affinity of the Triton-wt complex for host proteins may also relate to the unique conformation formed upon complex formation. This ability to bind to a variety of extracellular matrix (ECM) proteins may play an important role in $P$. gingivalis virulence as adherence to ECM proteins has been reported to be a crucial step in the pathogenic process associated with many bacteria (Schwarz-Linek et al., 2004). Similar to other microbial surface proteins that bind ECM proteins, the RgpA-Kgp complex can also be considered to be part of the family of cell-surface adhesin molecules called MSCRAMMs (microbial surface components recognizing adhesive matrix molecules) (Patti et al., 1994; Schwarz-Linek et al., 2004). The adherence of the proteinase-adhesin complexes to collagen type $\mathrm{V}$ may be an important factor in the reported links between periodontitis and cardiovascular diseases and preterm birth of infants (Beck et al., 1998; Offenbacher et al., 1998; Spahr et al., 2006). Collagen type V is located in the basement membrane of human aortas, arteries and atherosclerotic plaques. It is also found in the endothelial basement membranes of the placenta and in the amniotic basement membrane (Merker et al., 1987; Polzin et al., 1997). The relative concentration of collagen type $\mathrm{V}$ has been reported to increase during the development and ageing of the placenta (Iwahashi et al., 1996).

In conclusion, we have developed a simple and efficient method for the extraction and purification of the complexes of the processed domains of RgpA, Kgp and HagA from $P$. gingivalis using Triton X-114 and Arg-affinity chromatography. The Triton-extracted complexes bound at high affinity to a range of host proteins and when used as an immunogen provided protection against challenge with $P$. gingivalis in a murine model of infection.

\section{ACKNOWLEDGEMENTS}

The authors would like to thank Dina Chen for assistance with mass spectrometry. The $P$. gingivalis W501 and K1A mutants were kindly provided by M. A. Curtis (St Bartholomew's and The Royal London School of Medicine \& Dentistry, London, UK). This work was supported by the Australian National Health and Medical Research Council (project No. 251708) and the National Institute of Health (grant no. 1R01DE14198-01). Dr Neil M. O’Brien-Simpson is a C. R. Roper Fellow.

\section{REFERENCES}

Baker, P. J., Evans, R. T. \& Roopenian, D. C. (1994). Oral infection with Porphyromonas gingivalis and induced alveolar bone loss in immunocompetent and severe combined immunodeficient mice. Arch Oral Biol 39, 1035-1040.

Beck, J. D., Offenbacher, S., Williams, R., Gibbs, P. \& Garcia, R. (1998). Periodontitis: a risk factor for coronary heart disease? Ann Periodontol 3, 127-141.

Bedi, G. S. \& Williams, T. (1994). Purification and characterization of a collagen-degrading protease from Porphyromonas gingivalis. J Biol Chem 269, 599-606.

Bhogal, P. S., Slakeski, N. \& Reynolds, E. C. (1997). A cellassociated protein complex of Porphyromonas gingivalis W50 composed of Arg- and Lys-specific cysteine proteinases and adhesins. Microbiology 143, 2485-2495.

Bordier, C. (1981). Phase separation of integral membrane proteins in Triton X-114 solution. J Biol Chem 256, 1604-1607.

Brooks, C. S., Vuppala, S. R., Jett, A. M. \& Akins, D. R. (2006). Identification of Borrelia burgdorferi outer surface proteins. Infect Immun 74, 296-304.

Brown, L. J., Johns, B. A. \& Wall, T. P. (2000). The economics of periodontal diseases. Periodontology 29, 223-234.

Chen, Z., Potempa, J., Polanowski, A., Wikstrom, M. \& Travis, J. (1992). Purification and characterization of a $50-\mathrm{kDa}$ cysteine proteinase (gingipain) from Porphyromonas gingivalis. J Biol Chem 267, 18896-18901.

Cohen, J. (1969). Statistical Power Analysis for the Behavioral Sciences. New York: Academic Press.

Cullen, P. A., Cordwell, S. J., Bulach, D. M., Haake, D. A. \& Adler, B. (2002). Global analysis of outer membrane proteins from Leptospira interrogans serovar Lai. Infect Immun 70, 2311-2318.

Curtis, M. A., Kuramitsu, H. K., Lantz, M., Macrina, F. L., Nakayama, K., Potempa, J., Reynolds, E. C. \& Aduse-Opoku, J. (1999). Molecular genetics and nomenclature of proteases of Porphyromonas gingivalis. J Periodontal Res 34, 464-472.

Evans, R. T., Klausen, B., Ramamurthy, N. S., Golub, L. M., Sfintescu, C. \& Genco, R. J. (1992). Periodontopathic potential of two strains of Porphyromonas gingivalis in gnotobiotic rats. Arch Oral Biol 37, 813-819.

Fujimura, S., Hirai, K., Shibata, Y., Nakayama, K. \& Nakamura, T. (1998). Comparative properties of envelope-associated argininegingipains and lysine-gingipain of Porphyromonas gingivalis. FEMS Microbiol Lett 163, 173-179. 
Iwahashi, M., Ooshima, A. \& Nakano, R. (1996). Increase in the relative level of type $\mathrm{V}$ collagen during development and ageing of the placenta. J Clin Pathol 49, 916-919.

Jain, A., Batista, E. L., Jr, Serhan, C., Stahl, G. L. \& Van Dyke, T. E. (2003). Role for periodontitis in the progression of lipid deposition in an animal model. Infect Immun 71, 6012-6018.

Knibbs, R. N., Takagaki, M., Blake, D. A. \& Goldstein, I. J. (1998). The role of valence on the high-affinity binding of Griffonia simplicifolia isolectins to type A human erythrocytes. Biochemistry 37, 16952-16957.

Kontani, M., Ono, H., Shibata, H., Okamura, Y., Tanaka, T., Fujiwara, T., Kimura, S. \& Hamada, S. (1996). Cysteine protease of Porphyromonas gingivalis 381 enhances binding of fimbriae to cultured human fibroblasts and matrix proteins. Infect Immun 64, 756-762.

Lamont, R. J. \& Jenkinson, H. F. (2000). Subgingival colonization by Porphyromonas gingivalis. Oral Microbiol Immunol 15, 341-349.

Lin, D., Smith, M. A., Champagne, C., Elter, J., Beck, J. \& Offenbacher, S. (2003). Porphyromonas gingivalis infection during pregnancy increases maternal tumor necrosis factor alpha, suppresses maternal interleukin-10, and enhances fetal growth restriction and resorption in mice. Infect Immun 71, 5156-5162.

Mercado, F. B., Marshall, R. I., Klestov, A. C. \& Bartold, P. M. (2001). Relationship between rheumatoid arthritis and periodontitis. J Periodontol 72, 779-787.

Merker, H. J., Bremer, D., Barrach, H. J. \& Gossrau, R. (1987). The basement membrane of the persisting maternal blood vessels in the placenta of Callithrix jacchus. Anat Embryol 176, 87-97.

Mikolajczyk, J., Boatright, K. M., Stennicke, H. R., Nazif, T., Potempa, J., Bogyo, M. \& Salvesen, G. S. (2003). Sequential autolytic processing activates the zymogen of Arg-gingipain. J Biol Chem 278, 10458-10464.

Miyakawa, H., Honma, K., Qi, M. \& Kuramitsu, H. K. (2004). Interaction of Porphyromonas gingivalis with low-density lipoproteins: implications for a role for periodontitis in atherosclerosis. J Periodontal Res 39, 1-9.

Mortz, E., Vorm, O., Mann, M. \& Roepstorff, P. (1994). Identification of proteins in polyacrylamide gels by mass spectrometric peptide mapping combined with database search. Biol Mass Spectrom 23, 249-261.

O'Brien-Simpson, N. M., Paolini, R. A. \& Reynolds, E. C. (2000). RgpA-Kgp peptide-based immunogens provide protection against Porphyromonas gingivalis challenge in a murine lesion model. Infect Immun 68, 4055-4063.

O'Brien-Simpson, N., Veith, P. D., Dashper, S. G. \& Reynolds, E. C. (2003). Porphyromonas gingivalis gingipains: the molecular teeth of a microbial vampire. Curr Protein Pept Sci 4, 409-426.

O'Brien-Simpson, N. M., Veith, P. D., Dashper, S. G. \& Reynolds, E. C. (2004). Antigens of bacteria associated with periodontitis. Periodontology 35, 101-134.

O'Brien-Simpson, N., Pathirana, R., Paolini, R. A., Chen, Y.-Y., Veith, P. D., Tam, V., Ally, N., Pike, R. \& Reynolds, E. C. (2005). An immune response directed to proteinase and adhesin functional epitopes protects against Porphyromonas gingivalis-induced periodontal bone loss. J Immunol 175, 3900-3989.

Offenbacher, S., Jared, H. L., O'Reilly, P. G., Wells, S. R., Salvi, G. E., Lawrence, H. P., Socransky, S. S. \& Beck, J. D. (1998). Potential pathogenic mechanisms of periodontitis associated pregnancy complications. Ann Periodontol 3, 233-250.

Paramonov, N., Rangarajan, M., Hashim, A., Gallagher, A., Aduse-Opoku, J., Slaney, J. M., Hounsell, E. \& Curtis, M. A. (2005). Structural analysis of a novel anionic polysaccharide from
Porphyromonas gingivalis strain W50 related to Arg-gingipain glycans. Mol Microbiol 58, 847-863.

Patti, J. M., Allen, B. L., McGavin, M. J. \& Hook, M. (1994). MSCRAMM-mediated adherence of microorganisms to host tissues. Annu Rev Microbiol 48, 585-617.

Persson, G. R., Engel, D., Whitney, C., Darveau, R., Weinberg, A., Brunsvold, M. \& Page, R. C. (1994). Immunization against Porphyromonas gingivalis inhibits progression of experimental periodontitis in nonhuman primates. Infect Immun 62, 1026-1031.

Pike, R., McGraw, W., Potempa, J. \& Travis, J. (1994). Lysine- and arginine-specific proteinases from Porphyromonas gingivalis. Isolation, characterization, and evidence for the existence of complexes with hemagglutinins. J Biol Chem 269, 406-411.

Pike, R. N., Potempa, J., McGraw, W., Coetzer, T. H. \& Travis, J. (1996). Characterization of the binding activities of proteinaseadhesin complexes from Porphyromonas gingivalis. J Bacteriol 178, 2876-2882.

Polzin, W. J., Lockrow, E. G. \& Morishige, W. K. (1997). A pilot study identifying type $\mathrm{V}$ collagenolytic activity in human amniotic fluid. Am J Perinatol 14, 103-106.

Potempa, J., Sroka, A., Imamura, T. \& Travis, J. (2003). Gingipains, the major cysteine proteinases and virulence factors of Porphyromonas gingivalis: structure, function and assembly of multidomain protein complexes. Curr Protein Pept Sci 4, 397-407.

Pucher, J. \& Stewart, J. (2004). Periodontal disease and diabetes mellitus. Curr Diab Rep 4, 46-50.

Qiu, X., Schroeder, P. \& Bridon, D. (1996). Identification and characterization of a $\mathrm{C}(\mathrm{K} / \mathrm{R}) \mathrm{TC}$ motif as a common epitope present in all subtypes of hepatitis B surface antigen. J Immunol 156, 3350-3356.

Radolf, J. D., Chamberlain, N. R., Clausell, A. \& Norgard, M. V. (1988). Identification and localization of integral membrane proteins of virulent Treponema pallidum subsp. pallidum by phase partitioning with the nonionic detergent triton X-114. Infect Immun 56, 490498.

Rajapakse, P. S., O'Brien-Simpson, N. M., Slakeski, N., Hoffmann, B. \& Reynolds, E. C. (2002). Immunization with the RgpA-Kgp proteinase-adhesin complexes of Porphyromonas gingivalis protects against periodontal bone loss in the rat periodontitis model. Infect Immun 70, 2480-2486.

Schwarz-Linek, U., Hook, M. \& Potts, J. R. (2004). The molecular basis of fibronectin-mediated bacterial adherence to host cells. Mol Microbiol 52, 631-641.

Slakeski, N., Bhogal, P. S., O’Brien-Simpson, N. M. \& Reynolds, E. C. (1998). Characterization of a second cell-associated Arg-specific cysteine proteinase of Porphyromonas gingivalis and identification of an adhesin-binding motif involved in association of the prtR and prtK proteinases and adhesins into large complexes. Microbiology 144, 1583-1592.

Slakeski, N., Cleal, S. M., Bhogal, P. S. \& Reynolds, E. C. (1999). Characterization of a Porphyromonas gingivalis gene prtK that encodes a lysine-specific cysteine proteinase and three sequence-related adhesins. Oral Microbiol Immunol 14, 92-97.

Slots, J. (1982). Importance of black-pigmented Bacteroides in human periodontal disease. Host parasite interactions in periodontal diseases. In Host-parasite Interactions in Periodontal Diseases, pp. 27-45. Edited by R. Genco \& S. E. Merganhagan. Washington, DC: American Society for Microbiology.

Socransky, S. S. \& Haffajee, A. D. (2000). Dental biofilms: difficult therapeutic targets. Periodontology 28, 12-55.

Socransky, S. S., Haffajee, A. D., Cugini, M. A., Smith, C. \& Kent, R. L., Jr (1998). Microbial complexes in subgingival plaque. J Clin Periodontol 25, 134-144. 
Spahr, A., Klein, E., Khuseyinova, N. \& 7 other authors (2006). Periodontal infections and coronary heart disease: role of periodontal bacteria and importance of total pathogen burden in the Coronary Event and Periodontal Disease (CORODONT) study. Arch Intern Med 166, 554-559.

Suckau, D., Resemann, A., Schuerenberg, M., Hufnagel, P., Franzen, J. \& Holle, A. (2003). A novel MALDI LIFT-TOF/TOF mass spectrometer for proteomics. Anal Bioanal Chem 376, 952-965.

Takii, R., Kadowaki, T., Baba, A., Tsukuba, T. \& Yamamoto, K. (2005). A functional virulence complex composed of gingipains, adhesins, and lipopolysaccharide shows high affinity to host cells and matrix proteins and escapes recognition by host immune systems. Infect Immun 73, 883-893. van Winkelhoff, A. J., Loos, B. G., van der Reijden, W. A. \& van der Velden, U. (2002). Porphyromonas gingivalis, Bacteroides forsythus and other putative periodontal pathogens in subjects with and without periodontal destruction. J Clin Periodontol 29, 1023-1028.

Veith, P. D., Talbo, G. H., Slakeski, N., Dashper, S. G., Moore, C., Paolini, R. A. \& Reynolds, E. C. (2002). Major outer membrane proteins and proteolytic processing of RgpA and Kgp of Porphyromonas gingivalis W50. Biochem J 363, 105-115.

Wu, T., Trevisan, M., Genco, R. J., Falkner, K. L., Dorn, J. P. \& Sempos, C. T. (2000). Examination of the relation between periodontal health status and cardiovascular risk factors: serum total and high density lipoprotein cholesterol, C-reactive protein, and plasma fibrinogen. Am J Epidemiol 151, 273-282. 